\title{
Higher Education Non-Completion, Employers, and Labor Market Integration: \\ Experimental Evidence
}

\author{
Martin Neugebauer* \\ Annabell Daniel \\ Freie Universität Berlin \\ Ludwig-Maximilians-Universität Munich
}

\section{Forthcoming in Social Science Research}

\begin{abstract}
Theories of job assignment suggest that employers give a lot of weight to achieved educational credentials. But what if credentials are missing? We theorize how college noncompletion affects the hiring chances, identify its causal effect in different labor market segments, and assess which factors facilitate labor market entry for dropouts. Based on a simulated hiring process with $N=1,382$ German employers who rated more than 10,000 fictitious CVs, we show that college non-completion is not a scar per se, but rather depends on the educational attainment of the competitors who constitute the labor queue, and on the degree of occupational closure which varies on a granular level between firms that hire for the same occupations. We also find that employers, when rating dropouts, attach most value to $\mathrm{CV}$ attributes that signal a high stock of job-relevant skills, such as good performance during college or an occupation-specific internship. We conclude by discussing implications of our work for research on the labor market integration of dropouts.
\end{abstract}

Keywords: College dropout, incomplete degree, returns to education, employer behavior, factorial survey experiment, Germany

*Direct correspondence to: Martin Neugebauer (martin.neugebauer@,fu-berlin.de), Department of Education and Psychology, Freie Universität Berlin, Habelschwerdter Allee 45, D-14195 Berlin, Germany. This work was supported by the German Federal Ministry of Education and Research (grant number 01PX16012 to M.N.). We thank Rainer Watermann and Peter Steiner for supporting us during the design of the study. We are grateful for valuable comments from Daniel Klein, Walter Müller, the editor and reviewers of SSR. Parts of this article were presented at the ECSR Conference in Lausanne, and meetings at the WZB and the DZHW. We thank all participants for their helpful feedback. 


\section{Introduction}

The massive expansion of higher education (HE) across the world has been accompanied by an increase in people who fail to obtain the single most important college outcome: a degree (Bowen et al. 2009: 32). According to the Organisation for Economic Co-operation and Development (OECD), one third of all HE entrants leave without graduating (OECD 2013: 71). As today more than $50 \%$ of young adults in OECD-countries enter a bachelor's or equivalent program (OECD 2019: 193), this amounts to millions of people who try to enter the labor market without a degree. ${ }^{1}$ How do employers react to this new reality, in which so many applicants hope that an unfinished degree does not exclude them from accessing their aspired careers? In this study, we investigate two questions: (RQ1) What is the causal effect of incomplete higher education on the hiring chances in different labor market segments? (RQ2) Which factors facilitate labor market entry for dropouts?

Studying the nexus between education and labor market outcomes has been a central topic of social science research for decades (e.g. Shavit and Müller 1998; Di Prete et al. 2017). But despite the prevalence of the dropout phenomenon, most studies measure merely the highest degree obtained, and non-completers fall back to the previous level completed. In consequence, while countless studies document and theorize on the labor market consequences of successfully attained qualifications, much less is known about the consequences of unsuccessfully attempted qualifications. This is unfortunate because individuals are unaware of the potential outcomes of their educational choices. For example, it is an unsettled question whether there is an individual cost (or a scar) to educational failure, as the widely cited educational decision model by Breen and Goldthorpe (1997) assumes (Hällsten 2017). It is also unclear how employers select candidates for jobs, when a key signal of the candidates' skills and trainability - a degree - is missing. Furthermore, it is uncertain how the presumably negative consequences of discontinued education can be reduced if an individual perceives withdrawal as the only viable path. From a societal perspective, unfinished degrees are often seen as a waste of public resources, a source of foregone tax revenues, and a disadvantage in the global competition of knowledge economies (e.g. Schneider and Yin 2011). However, such macro-level disadvantages materialize only if noncompleters systematically fail to integrate well into the labor market.

A number of studies has investigated labor market outcomes of persons who have left HE prior to receiving a degree. These studies generally find that persons with "some college" achieve 
lower earnings or job statuses than HE graduates (US: Flores-Lagunes and Light 2010; Hungerford and Solon 1987; Kane and Rouse 1995; Light and Strayer 2004; GB: Davies and Elias 2003; Johnes and Taylor 1991; DE: Heigle and Pfeiffer 2019, Scholten and Tieben 2017; RS/HR: Matkovic and Kogan 2012). Less clear are comparisons of the "some college" group with those who never enter HE. Few of these studies find that persons with some college are worse off (SE: Hällsten 2017; IT: Ghignoni et al. 2019), some find they are similar (US: Rosenbaum et al. 2015; Grubb 2002; RS/HR: Matkovic and Kogan 2012; DE: Heigle and Pfeiffer 2019), while others suggest incomplete degrees do pay off to varying degrees (US: Giani et al. 2020; Kane and Rouse 1995; Light and Strayer 2004; 15 EU countries: Schnepf 2017). Part of this ambiguity is due to different country contexts, samples, and estimation strategies, calling for further research to resolve these issues. However, we see more fundamental shortcomings in the literature that we aim to address here.

Most previous studies lump together persons that are very heterogeneous in terms of fields of study, and aspired occupations. For instance, if students in STEM-fields have a higher likelihood to withdraw than humanities students, while at the same time they are more likely to apply for high paying occupations, labor market disadvantages of dropouts may be underestimated. To evaluate the individual ramifications of an unfinished degree, comparisons with otherwise similar persons without a dropout experience applying for similar jobs are indispensable. Furthermore, the mentioned studies all relied on supply-side data of former students which we believe is problematic for two reasons: (1) Given the inherent self-selection bias in who chooses to attend HE (vs. not), and who completes the degree (vs. not), a major challenge with such data is unobserved heterogeneity. For instance, Giani et al. (2020) used administrative cohort data from Texas to compare the employment and earnings of those who did not go beyond high school with those who had entered college but did not complete a credential. While they were able to control for group differences in academic skills and socio-demographic backgrounds, they were unable to control for other confounders that influence both the educational decision and labor market success, such as aspirations, self-efficacy, or conscientiousness. (2) The demand-side of hiring has received little attention, despite the pivotal role of employers in granting access to the labor market (Bills et al. 2017). How employers interpret, and respond to incomplete education is essential to understand why dropouts get jobs (or not), and subsequently why they realize the above mentioned labor market benefits, such as employment or wages. Supply-side studies can guess employers' 
evaluations only indirectly and in retrospect, rather than empirically demonstrate their reactions. Following this line of argument, recent scholarship has impressively shown how demand-side studies are of critical importance to our understanding of how non-standard employment histories - such as unemployment, freelancing, or parental leaves - influence hiring decisions and contribute to labor market stratification (e.g. Pedulla 2016; Ma 2020; Weisshaar 2018). We argue that similar attention should be devoted to non-standard education histories, most importantly, non-completion. While current contributions have focused on specific aspects of education, such as for-profit degrees or study duration (e.g. Deterding and Pedulla 2016; Baert and Picchio 2021), the fact that many students leave college without a degree, has been largely overlooked by this literature (exception: Di Stasio and van de Werfhorst 2016).

To address these issues, we complement existing research by simulating a hiring process with $N=1,382$ randomly sampled employers in the German labor market who were asked to rate a total of $N=11,056$ experimentally varied CVs (vignettes). In a first step, we compare the hiring chances of dropouts and their typical competitors in three different segments of the labor market: apprenticeship positions, skilled worker positions, and HE graduate positions. Because the educational attainment of the competitors varies systematically across these labor market segments, we can test a central assumption of the job assignment process, namely, that hiring chances should depend on the amount of education relative to the educational attainment of other job applicants (i.e. the labor queue, Thurow 1975). Our findings confirm that a fixed educational signal, here, non-completion, leads to very different hiring chances conditional on distribution of educational attainment in the labor queue. Furthermore, because we have firm-specific information on closure by degree, we can assess the contribution of credentialing for the labor market disadvantages of non-degree holders. In a second step, we acknowledge that there is no such thing as the dropout. Individuals with incomplete education differ not only in the paths they seek to enter the labor market, but also with respect to other characteristics, such as the length of the HE episode, or the grades they achieved, and these factors are likely to influence their hiring chances. We vary such factors in our study to estimate which factors can potentially facilitate labor market entry.

Our paper contributes to the small but growing literature on the labor market consequences of HE non-completion by incorporating the demand side of hiring. We argue that this perspective has four main advantages over previous research: (1) It gives us the opportunity to theorize the role of (lacking) degrees in highly standardized and regulated education systems like the German one 
from a demand-side perspective, thereby nuancing theories of job assignment. (2) It allows for a more precise estimation of ceteris paribus effects of college non-completion. (3) It enables us to single out the importance of a dropout signal vis-à-vis other signals typically sent in CVs to infer the relative importance of the effect. (4) From a more practical perspective, our findings can help to inform students and career counselling, because they provide indications such as how to optimize labor market entries in case of an imminent dropout.

\section{Theoretical Background}

\section{The Link Between Education and Occupation from an Employer's Perspective}

The transition from education to the first job is a central stage in the life-course with longlasting consequences for later working life (e.g. Blossfeld 1987). While decades of research have investigated this transition using supply-side data, recent sociological research has stressed the importance of the demand-side (Bills 1988; Bills et al. 2017; Damelang et al. 2020; Di Stasio and van de Werfhorst 2016; Jackson 2007; Rivera 2020; Shi and Wang 2021). This literature argues that employers are the central gatekeepers of the labor market. In the two-sided matching process between job-seekers and job-vacancies (Jovanovic 1979), it is their perceptions and actions that ultimately determine who gets jobs - and why. In this context, theories of job assignment suggest that employers give a lot of weight to achieved educational credentials (see Bills 2003 for a review). According to human capital theory, education provides skills and knowledge that are valued by employers (Becker 1964). When making their hiring decisions, however, employers face the challenge that the human capital of job applicants is not perfectly observable. Therefore, employers rely on signals for future productivity and trainability, as argued by signaling and screening theories (Arrow 1973; Spence 1973). In these theories, educational credentials stand out as the key signaling device that employers use to screen and select the best applicants. Thurow (1975) emphasizes that employers rank job seekers in a queue to select the best candidates. Thus, hiring decisions also depend on the quality of competitors, making educational credentials a positional good. Finally, employers can use educational credentials as a closure devise to regulate access to rewarding occupations that are closed to non-degree holders (Bol and Weeden 2015; Weeden 2002). While the theories differ in the role they assign to educational credentials, which can be skill-enhancing, skill-signaling, or an entry ticket to rewarding occupations, the theories agree on 
their pivotal role in the job-matching process. What happens if an educational credential is missing, as in the case of those who withdraw prior to receiving a HE degree?

\section{The Institutional Context}

An interesting test case to study this question is Germany, which is the prime example of a country with strong linkages between educational qualifications and occupational destinations (e.g. Allmendinger 1989; Di Prete et al. 2017; Shavit and Müller 1998). Characterized by a vocationally oriented and tracked educational system, degrees in Germany convey detailed and reliable information about the skills that a degree-holder possesses, and employers can readily rely on them to reduce uncertainty about job seekers' productivity (Bol and van de Werfhorst 2011; van de Werfhorst 2011). The link between degrees and occupations in the German labor market is tight not only in the vocational segment but also at the tertiary level (Leuze 2007). In consequence, lacking this signaling device should put non-completers at a strong disadvantage. Furthermore, closure is pronounced in the German labor market (Bol and Weeden 2015), which is highly structured along occupations (Marsden 1990). However, the picture is more complex. In line with Thurow's (1975) queuing argument, hiring chances depend on the relative standing of dropouts vis-à-vis their typical competitors, and thus, on the type of position they apply for. In the German context, dropouts typically take one of three pathways into the labor market, depending on the time point of dropping out (Neugebauer et al. 2019): As depicted in figure 1, most of the early dropouts apply for an apprenticeship position in the dual system of vocational education and training (VET). By combining school-based theoretical learning with firm-based training, VET facilitates the transition from education to work. Thereby, VET may offer a 'safety net' that protects dropouts from entering unemployment or unskilled occupations. In particular, dropouts choose apprenticeships in the upper vocational segment (such as computer science expert or banking professional) that are usually filled by upper secondary school leavers with a university entrance qualification (BIBB 2020). A second option is to apply for skilled worker positions in the vocational segment of the labor market, where (mostly late) dropouts compete with job-seekers who have completed an apprenticeship and obtained a VET certificate. A third option is to apply for positions advertised for HE graduates, where most competitors have completed tertiary education. $^{2}$ 
Figure 1: Pathways into Employment after HE non-completion and Typical Competitors

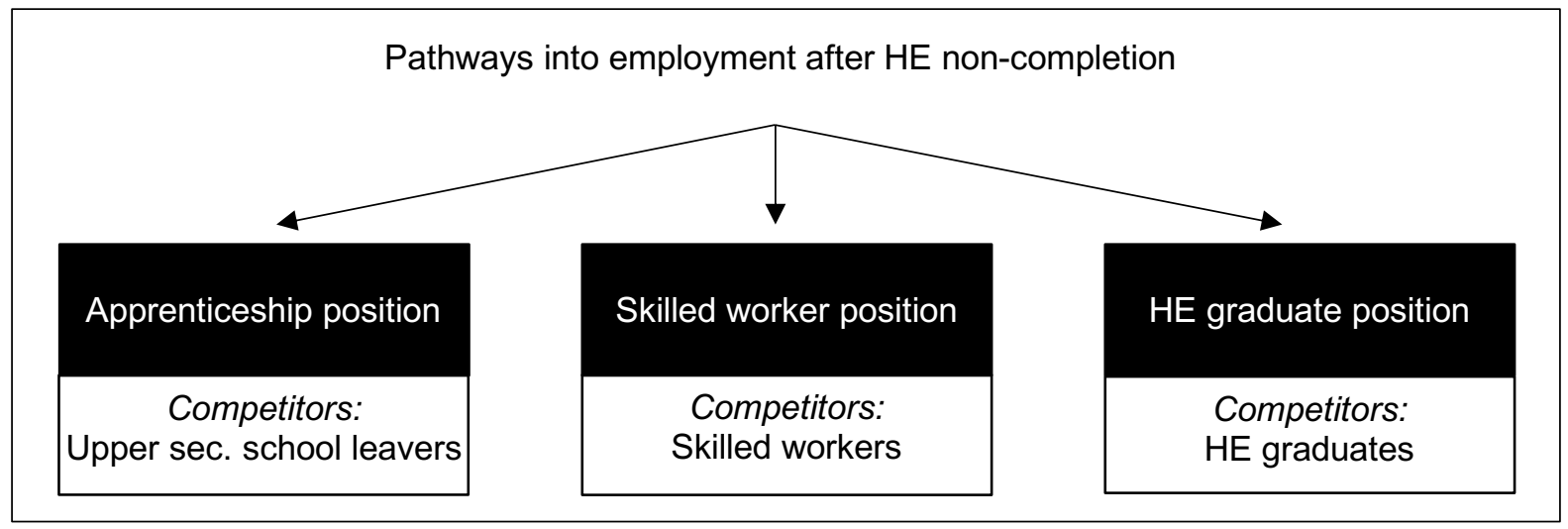

Unlike prior research, which has largely ignored the contextual nature of the career start of students with some college, we have included these different entry ports and the resulting competitive situations when estimating their hiring chances. More precisely, we let dropouts apply for jobs in all three labor market segments in three separate studies. Our design allows us to investigate causal effects for three counterfactual scenarios: What would have happened had a dropout a) applied for an apprenticeship right away without trying to succeed in HE?; b) started and finished a vocational education and training (VET) and then applied for a skilled labor market position instead of applying there as a HE dropout?; or c) completed HE before applying for a HE graduate position?

\section{Hiring Chances for Dropouts vis-à-vis Their Typical Competitors at the Three Entry Ports}

In this section, we theorize about the hiring chances of dropouts under the three counterfactual scenarios, beginning with (a) apprenticeship positions. According to the skill-enhancing argument put forward by human capital theory, HE dropouts should have better hiring chances vis-à-vis school leavers, as long as they used their HE episode to accumulate some skills and knowledge that are valued by employers. The predictions with respect to signaling theory are less clear. On the one hand, the event of dropping out can be interpreted as a lack of perseverance or low cognitive ability, on the other hand, dropouts may be perceived as more mature and experienced. In line with the second interpretation, Daniel et al. (2019) showed that dropouts were slightly more likely to be invited to job interviews compared to otherwise similar upper secondary school leavers. Thus, while we are hesitant to assume clear advantages of individuals with incomplete education, 
we expect that (H1) dropouts are not disadvantaged when applying for apprenticeship positions vis-à-vis upper secondary school leavers.

For (b) skilled worker positions, our expectations differ: In the dual system, apprentices acquire occupation-specific skills at vocational schools and the work place, and the vocationspecific training follows nationally defined standards and quality controls (Solga et al. 2014). Job seekers with a VET degree possess this occupation-specific human capital, unlike HE dropouts, who have to adapt to the job requirements even if they studied in a related field for a similar amount of time. With respect to signaling, dropouts should have considerable difficulties indicating their ability and trainability without the expected VET degree, especially in an institutional setting like Germany, were the signaling capacity of a VET degree is high and reliable. For Germany, supplyside data lends support to this argument with a study showing that dropouts have lower chances to enter a stable employment than graduates from vocational training (Scholten and Tieben 2017). Thus, we expect that (H2) dropouts are disadvantaged when applying for skilled worker positions.

For (c) graduate positions, human capital theory does not predict different hiring chances for dropouts and graduates, if the only difference between them is a certificate. ${ }^{3}$ The signaling arguments are, however, similar to the skilled worker positions above: credentials signal potential productivity and skills, and probably also perseverance or other favorable non-cognitive traits, and dropouts are lacking this signaling device. In line with this reasoning, supply-side studies from Germany comparing graduates and dropouts detected considerable disadvantages of dropouts in terms of earnings (Heigle and Pfeiffer 2019), and occupational status (Scholten and Tieben 2017). In consequence, we assume that even in an experimental 'ceteris paribus' setting (H3) dropouts are disadvantaged when applying for HE graduate positions.

For (b) and (c), a further argument for dropouts' disadvantages is closure by educational credentialing. Access to skilled worker and graduate positions is sometimes closed to non-degree holders (Bol and Weeden 2015; Haupt 2016). While closure limits the applicant pool, it helps employers to identify who is well-trained to perform the job tasks and it may ensure certain standards among job holders. In line with this reasoning, Di Stasio and van de Werfhorst (2016) and Di Stasio (2014) report relatively large penalties for non-degree holders in Italy, the Netherlands, and England. Because closure is common in the German labor market, we expect that (H4) disadvantages of dropouts in the skilled and graduate labor market are partly driven by occupational closure. 


\section{Factors Facilitating Labor Market Entry for Dropouts}

Up to this point, we have acknowledged that dropouts differ in the paths they seek to enter the labor market, but we have ignored that there is no such thing as the dropout. Individuals with incomplete education differ with respect to the length of the HE episode or the grades they achieved, and these factors are likely to influence their hiring chances. Knowledge on how employers react to different characteristics of the HE episode is important for individuals facing withdrawal and for HE institutions advising them. For example, does postponing withdrawal to a later semester help labor market integration, or does it simply increase individual and institutional costs? Relatedly, should a person contemplating to withdraw continue to strive for good grades and be advised to do so, or does college non-completion override any subtle differences in the eyes of employers? Nuanced investigations along these lines are challenging with supply-side data, because it remains unclear which aspects employers actually pick up on, and because different signals are typically correlated with unobserved characteristics such as innate ability. Accordingly, previous research has treated dropouts largely as a homogenous group, ignoring important variation between them. A factorial survey experiment with employers, however, allows for simultaneous variation of different dropout characteristics, to causally estimate their relevance in hiring decisions.

Theoretically, we assume that good grades, a job-related internship, job-related course work, and job-related informal skills (e.g. acquired through spare-time work) should increase jobrelevant skills (human capital) or indicate high ability and interest in the job, thereby lowering the training costs for employers (signaling). This should be true for dropouts in all three labor market segments. Empirically, Daniel et al. (2019) lend support to these assumptions, but their analysis is limited to apprenticeship positions. Further support comes from studies that have investigated the value of particular CV attributes for graduates' (not dropouts') labor market chances (Di Staso 2014; Di Stasio and van de Werfhorst 2016; Humburg and van der Velden 2015; Piopiunik et al. 2020). Because we have no reason to believe this to be different among dropouts we expect that (H5) a high grade point average, a job-related internship, a close match between the field of study and the job tasks, and job-related informal skills increase the hiring chances of dropouts for all types of positions.

Our predictions with respect to the length of the study episode are mixed. While a late dropout might increase human capital or the signal thereof, it might also be perceived as a waste of time 
(Schnepf 2017). We assume that the signal is dependent on the chosen labor market entry port. For apprenticeships, where job training occurs after hiring, previous research has indicated that employers prefer younger applicants, who can be more easily integrated into the social context of the work place (Imdorf 2012). For skilled worker and graduate positions, however, employers should expect job incumbents to possess a set of skills required to fulfill the job tasks. We suspect that dropouts with a short HE episode cannot possess these skills. If anything, employers may consider to hire dropouts with longer tertiary training, who do not possess the educational certificate, but possibly possess the required competencies. Of course, this is only true if the jobs are not closed to non-degree holders. In sum, we hypothesize that (H6) a longer study episode lowers the hiring chances for apprenticeships, but raises the hiring chances for skilled and graduate positions.

In recent years, a growing literature has shown that English foreign language skills as well as international student mobility are gaining importance among HE graduates. While English proficiency seems to be expected from all applicants in this labor market segment and does not have significant effects (Piopiunik et al. 2020), abroad experiences positively impact labor market outcomes of graduates in a globalized world (e.g. Humburg and van de Velden 2015; Jacob, Kühhirt, and Rodrigues 2019). It is assumed that abroad experiences foster (or signal) skills necessary to adapt to a new country, such as the ability to self-organize and to be open-minded, which may also facilitate integration in a new job. We are unaware of any study that has examined these factors for individuals who have failed to complete HE. However, similarly to the cited college graduate studies, we assume that $(\mathrm{H7})$ an abroad study experience increases hiring chances for dropouts applying for graduate positions, while English proficiency has no impact.

\section{Methods}

We study hiring chances of dropouts and their typical competitors in the three labor market segments (apprenticeship positions, skilled worker positions, HE graduate positions) with three factorial survey experiments that we administered online (Auspurg and Hinz 2015). In simulated hiring processes, employers were presented with a series of fictitious CVs of applicants (i.e., vignettes), and asked to rate them according to their hiring chances. The method allows us to directly measure employers' hiring preferences. By experimentally varying $\mathrm{CV}$ characteristics, we can estimate the effects of different signals on employers' evaluations that are often highly 
correlated, such as low academic performance and HE withdrawal. Furthermore, we can exclude potential confounders as we have complete control over the information available to employers. Both the experimental design and the control over all input variables are ideal for identifying causal effects. For testing our hypotheses, we believe this method to be superior even to field experiments, such as audit studies. While in audit studies, the total number of applications send to one firm has to be restricted for ethical reasons, factorial survey experiments allow us to vary numerous characteristics simultaneously. This is particularly useful for investigating different factors that may facilitate labor market entry for dropouts (RQ2). Moreover, we have information on all applicants that an employer faces, contrary to audit studies, where the quality of competitors is unknown. Finally, factorial survey experiments can be accompanied by a questionnaire following the experiment, to collect further information about the firm. For instance, to test whether disadvantages of dropouts in the skilled and graduate labor market are partly driven by occupational closure (H4), we asked employers whether it is possible to fill a given position in their firm with someone who does not fulfill the formal educational requirements.

A common critique with survey experiments is that they only measure behavioral intentions. Previous research suggests, however, that applicant attributes estimated from survey experiments perform remarkably well in recovering the effects of the same attributes in real-world behavior (Hainmueller et al. 2015; Petzold and Wolbring 2019). Furthermore, we made a great effort to maximize the external validity of the survey experiments through our sampling strategy, and by constructing hiring scenarios as realistic as possible, as explained below.

\section{Respondent Sample}

For each labor market segment, our aim was to obtain a large, representative sample of persons responsible for personnel decisions. In each segment, we focused on two occupational fields, IT and business, for four reasons: First, jobs in these fields are widespread in all three labor market segments, enabling us to compare similar fields of activity at different labor market entry ports. Second, the corresponding fields of study (i.e., computer science and business administration) report high student numbers and high dropout rates (Heublein et al. 2017), which makes knowledge in these fields particularly relevant. Third, as both IT and business skills are in high demand by employers of various firms, graduates of computational science and business administration work in many different firms. By sampling employers hiring for IT and business 
jobs, we aimed to attain more heterogeneity in terms of economic sector, firm size and region, and thus greater generalizability of results even though our sample is restricted to two occupational fields. Fourth, apprenticeship positions in these fields are primarily filled by upper secondary school leavers as opposed to intermediate secondary school leavers (see BIBB 2020). This is important, because it allows us to compare dropouts with typical competitors who differ with respect to the aborted study episode, but not in terms of their school certificate.

To obtain a sample of persons in charge of hiring for IT and business jobs in each labor market segment, we programmed a web scraping tool to sample employers through real-world vacancies advertised in the most common online job portals. We constructed a list of common occupations for each segment * occupational field combination, such as computer science expert or management assistant for insurance and finance (see Appendix A in the online supplement). Based on this list, we collected all vacancies for up to ten months, before we drew a random sample of 2,000 vacancies from each segment * occupational field combination (12,000 in total), and invited the contact persons via the stated e-mail addresses. Overall, 1,382 respondents (response rate $11.5 \%, 55.2 \%$ female) participated in the survey, making our sample considerably larger than in previous studies. ${ }^{4}$ By design, all of them were working in firms that were recruiting personnel in the desired occupations. As Table 1 shows, respondents in our study work in firms of different sizes and in different economic sectors. They mainly work as general or human resource managers, and more than $98 \%$ of them have been responsible for personnel selection for 9.7 years on average. We refer to them as 'employers' in the remainder of the paper. As we show in Appendix B in the online supplement, respondents and non-respondents do not differ in a way that might change our substantive findings. 
Table 1: Employer Sample

\begin{tabular}{|c|c|c|c|c|}
\hline & $\begin{array}{l}\text { Apprenticeship } \\
\text { positions }\end{array}$ & $\begin{array}{l}\text { Skilled worker } \\
\text { positions }\end{array}$ & $\begin{array}{l}\text { HE graduate } \\
\text { positions }\end{array}$ & Total \\
\hline$N$ Employers & 695 & 352 & 335 & 1,382 \\
\hline$N$ Vignette ratings & 5,560 & 2,816 & 2,680 & 11,056 \\
\hline \multicolumn{5}{|l|}{ Hiring probability (\%) } \\
\hline Dropouts & 59.88 & 39.41 & 23.69 & 45.90 \\
\hline Typical competitors & 56.24 & 60.02 & 53.04 & 56.43 \\
\hline \multicolumn{5}{|c|}{ Employer characteristics - \% or M (SD) } \\
\hline Female & 54.49 & 47.79 & 62.42 & 54.66 \\
\hline Age & $41.89(10.92)$ & $40.85(11.63)$ & $39.22(10.58)$ & $41.01(11.03)$ \\
\hline \multicolumn{5}{|l|}{ Function } \\
\hline General management & 27.99 & 38.00 & 17.66 & 28.03 \\
\hline Human resources & 61.12 & 58.57 & 76.65 & 64.31 \\
\hline Operating dept. & 5.30 & 2.57 & 4.79 & 4.46 \\
\hline Other & 5.60 & 0.86 & 0.90 & 3.20 \\
\hline $\begin{array}{l}\text { Managerial responsibility } \\
(y / n)\end{array}$ & 43.84 & 72.17 & 54.02 & 52.90 \\
\hline $\begin{array}{l}\text { Involved in personnel } \\
\text { selection }(\mathrm{y} / \mathrm{n})\end{array}$ & 98.64 & 98.10 & 98.01 & 98.37 \\
\hline $\begin{array}{l}\text { Experience (years) in } \\
\text { personnel selection }\end{array}$ & $10.11(7.83)$ & $9.82(8.29)$ & $8.70(7.66)$ & $9.70(7.90)$ \\
\hline \multicolumn{5}{|c|}{ Firm characteristics $-\%$ or $\mathrm{M}(\mathrm{SD})$} \\
\hline \multicolumn{5}{|c|}{ Firm size } \\
\hline 0-49 employees & 30.35 & 49.79 & 46.59 & 38.26 \\
\hline 50-499 employees & 48.23 & 42.74 & 40.34 & 45.39 \\
\hline$\geq 500$ employees & 21.42 & 7.47 & 13.07 & 16.35 \\
\hline IT jobs (vs. business jobs) & 45.04 & 57.67 & 54.03 & 50.43 \\
\hline \multicolumn{5}{|l|}{ Sector $^{\mathrm{a}}$} \\
\hline Industry & 9.29 & 7.52 & 11.29 & 9.25 \\
\hline Market services & 82.15 & 85.29 & 77.82 & 82.06 \\
\hline Non-market services & 8.55 & 7.19 & 10.89 & 8.69 \\
\hline Candidate queue ${ }^{\mathrm{b}}$ & $2.70(0.63)$ & $2.55(0.69)$ & $2.65(0.70)$ & $2.66(0.67)$ \\
\hline $\begin{array}{l}\text { Closure: not possible to } \\
\text { hire someone who does } \\
\text { not fulfill the formal educ. } \\
\text { requirements }\end{array}$ & - & 25.86 & 33.75 & 29.71 \\
\hline
\end{tabular}

\section{Experimental Design and Variables}

To make the hiring simulation as realistic as possible, employers were first prompted with a hypothetical job offer that closely resembled the offer they had recently advertised on a job portal themselves (see Appendix $\mathrm{C}$ in the online supplement). Employers then had the task to indicate for a set of CVs of fictitious applicants, how likely they would hire this person on a 11-point scale 
from $0 \%$ to $100 \%$ for this job. In a preface to the vignettes, we informed employers that all applicants are labor market entrants, and that we only present to them applicants who convincingly stated their interest in the job in an error-free cover letter.

To answer our research questions, we constructed a vignette design that allows us to test for differences between individuals with incomplete education and their typical competitors in terms of hiring chances (RQ1), and to estimate the impact of various characteristics within dropouts (RQ2). Naturally, HE non-completion is associated with certain characteristics (e.g. length of the study episode) that vary among dropouts, but not among competitors who never enrolled in HE. As we are interested in precisely these characteristics, our solution was to split the vignette design by HE non-completion to form two sub-designs which are orthogonal both separately and combined - one consisting of vignettes describing HE dropouts and the other consisting of competitor vignettes. We will first outline how we created the dropout vignettes. The setup is similar across all labor market segments, with only a few differences.

The vignette dimensions of the fictitious CVs were designed according to theoretical considerations, as well as empirical findings of a pre-study in which we reviewed 30 real applications from dropouts and conducted qualitative interviews with 22 employers and three job counselors. $^{5}$

Table 2 shows all dimensions and associated levels. We varied academic performance in university indicated by GPA $(0=\operatorname{bad}(3.3), 1=\operatorname{good}(1.7))^{6}$, the time point of dropping out $(0=$ early ( $2^{\text {nd }}$ semester $), 1=$ late $\left(6^{\text {th }}\right.$ semester $)$ ), completion of an internship $(0=$ no, $1=3$-months internship), informally acquired skills $(0=$ no, $1=$ programming or stock consulting experience depending on the occupational field), and fit between field of study and aspired job ( $0=$ low, $1=$ high). In the experiment for $\mathrm{HE}$ graduate positions, we also varied English skills ( $0=$ intermediate $(\mathrm{B} 2), 1=$ proficient $(\mathrm{C} 1))$ and abroad experience $(0=$ no, $1=$ studied abroad for 1 semester $){ }^{7}$ To increase the external validity further, and to prevent fatigue effects when employers had to evaluate multiple vignettes, we varied additional characteristics that are mentioned in real-life CVs, such as applicants' GPA in upper secondary school $(0=$ bad $(2.9), 1=\operatorname{good}(1.8))$. In Appendix D in the online supplement we explain these in more detail. 
Table 2: Vignette Dimensions and Levels by Labor Market Segment

\begin{tabular}{|c|c|c|c|}
\hline Dimensions with 2 levels each & $\begin{array}{l}\text { Apprenticeship } \\
\text { positions }\end{array}$ & $\begin{array}{l}\text { Skilled worker } \\
\text { positions }\end{array}$ & $\begin{array}{l}\text { HE graduate } \\
\text { positions }\end{array}$ \\
\hline $\begin{array}{l}\text { (1) Academic performance (GPA) in university } \\
0=\operatorname{bad}(3.3), 1=\operatorname{good}(1.7)\end{array}$ & $\checkmark$ & $\checkmark$ & $\checkmark$ \\
\hline $\begin{array}{l}\text { (2) Dropout time point } \\
0=\text { early }\left(2^{\text {nd }} \text { sem. }\right), 1=\text { late }\left(6^{\text {th }} \text { sem. }\right)\end{array}$ & $\checkmark$ & $\checkmark$ & $\checkmark$ \\
\hline $\begin{array}{l}\text { (3) Job-relevant internship } \\
0=\text { no, } 1=3 \text { months internship }\end{array}$ & $\checkmark$ & $\checkmark$ & $\checkmark$ \\
\hline $\begin{array}{l}\text { (4) Informally acquired skills } \\
0=\text { no, } \\
1=\text { programming/stock consulting }\end{array}$ & $\checkmark$ & $\checkmark$ & $\checkmark$ \\
\hline $\begin{array}{l}\text { (5) Fit between field of study and aspired job }{ }^{\mathrm{a}} \\
0=\text { low, } 1=\text { high }\end{array}$ & $\checkmark$ & $\checkmark$ & $\checkmark$ \\
\hline $\begin{array}{l}\text { (6) English skills } \\
0=\text { intermediate (B2), } 1=\text { proficient }(\mathrm{C} 1)\end{array}$ & - & - & $\checkmark$ \\
\hline $\begin{array}{l}\text { (7) Abroad experience } \\
0=\text { no, } 1=\text { studied abroad for } 1 \text { sem. }\end{array}$ & - & - & $\checkmark$ \\
\hline $\begin{array}{l}\text { (8) Academic performance (GPA) in school } \\
0=\operatorname{bad}(2.9), 1=\operatorname{good}(1.8)\end{array}$ & $\checkmark$ & $\checkmark$ & $\checkmark$ \\
\hline $\begin{array}{l}\text { (9) Last school grade in German } \\
0=\operatorname{bad}(7 \text { points }), 1=\operatorname{good}(12 \text { points })\end{array}$ & $\checkmark$ & - & - \\
\hline $\begin{array}{l}\text { (10) Last school grade in math } \\
0=\text { bad ( } 7 \text { points }), 1=\text { good (12 points) }\end{array}$ & $\checkmark$ & - & - \\
\hline $\begin{array}{l}\text { (11) Sport hobby } \\
0=\text { individual (e.g. swimming), } \\
1=\text { team (e.g. basketball) }\end{array}$ & $\checkmark$ & - & - \\
\hline $\begin{array}{l}\text { (12) First name } \\
0=\text { lower class (e.g. Kevin), } \\
1=\text { middle class (e.g. Julius) }\end{array}$ & $\checkmark$ & $\checkmark$ & $\checkmark$ \\
\hline Vignette universe & $2^{10}=1024$ & $2^{7}=128$ & $2^{9}=512$ \\
\hline Fraction(dropouts) & 64 & 64 & 64 \\
\hline + Adoption for non-dropouts & $64 * 2=128$ & $64 * 2=128$ & $64 * 2=128$ \\
\hline Set size & $\begin{array}{l}16 \text { decks á } 8 \\
\text { vign. }\end{array}$ & $\begin{array}{l}16 \text { decks á } 8 \\
\text { vign. }\end{array}$ & $\begin{array}{l}16 \text { decks á } 8 \\
\text { vign. }\end{array}$ \\
\hline Resolution $^{\mathrm{c}}$ & IV & VII & IV \\
\hline
\end{tabular}

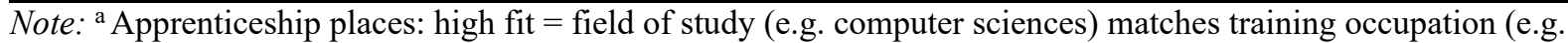
computer science expert). Low fit $=$ unmatched field of study (e.g. teacher training). Because of strong linkages in the skilled and graduate labor market, applications with unmatching fields of study are ecologically invalid. Here, we varied "fit" on a much smaller range: high fit = fitting course specialization within a fitting fos. Low fit = unfitting course specialization within a fitting fos (e.g. computer sciences with focus on system integration applying for a job as computer science expert in the area of software development as opposed to in the area of system integration). ${ }^{b}$ for apprenticeships: varied only among dropouts, because (soon to) graduate from upper secondary school applicants had no time for a 3-month internship before their application.

${ }^{\mathrm{c}} \mathrm{IV}=$ No main effects are confounded with two-factor interactions, but with three-factor (and higher) interactions; VII = No main effects are confounded with any other main effect or with four-factor (or less) interactions.

To reduce complexity, we used only male applicants with standard German-sounding names (see e.g. Quadlin 2018 for evidence on gendered hiring standards). Each vignette was displayed 
graphically as a one-page CV, resembling real-world CVs. In Germany, CVs typically include a photograph of the applicant. Photos in our studies were selected from the Chicago Face Database (Ma et al. 2015), and they were rated equally in terms of age and attractiveness by an independent rater sample. ${ }^{8}$ An example vignette is depicted in Figure 2.

Figure 2: Example Vignette (HE graduate positions)

Name
Jakob Roth vs. Pascal / Steven / Justin / Kevin
Study
Dropped out of computer science studies (B.A.) in the $6^{\text {th }}$ semester vs. $2^{\text {nd }}$ semester
Focus on software development vs. operating systems
(GPA 3.3) vs. 1.7
Education
2014- Higher entrance qualification
(GPA 1.8) vs. 2.9
Working experiences
Not specified vs. Three-months internship in a well-known IT-company
Experience abroad
Studied one semester abroad vs. Not specified
English proficiency
Intermediate (B2) vs. Proficient (C1)
Programming languages
Java, C++, Python
Other
Uses a scripting language to create modifications for video games vs. Not specified
How likely is it that you would hire Mr. Roth for the job?
$\quad \mathbf{3 0 \%}$
$\mathbf{0}$

Note: Dimensions that have been varied are with a grey background, alternative levels are indicated next to it. Example vignettes for the apprenticeship and the skilled worker market are depicted in Appendix E in the online supplement. Our qualitative pre-study showed that applicants sometimes try to hide their dropout episode (e.g. by mentioning a study program, but leaving out information on if and when a degree was obtained). However, employers reported that they nevertheless notice applicants' dropout when carefully checking the documents, or, in case of uncertainty, when calling the applicant to clarify this before inviting them to a job interview. By making the dropout status salient in the vignettes, we just facilitated employers' search for the crucial information they would become aware of sooner or later. 
For each labor market segment, a fraction of 64 vignettes was drawn from the respective universe and allocated to 16 sets à four vignettes (for details, see Appendix $\mathrm{F}$ in the online supplement). These sets constitute a very good representation of the corresponding universes in terms of orthogonality (zero correlation between dimensions overall and within sets; see Appendix $\mathrm{G}$ in the online supplement) and level balance (levels occur with the same frequency). This secures high statistical power and maximal precision of parameter estimates for analyzing the effects of factors facilitating the labor market entry within the group of dropouts (Dülmer 2016).

To generate the vignettes of typical competitors, we mirrored non-completion vignettes within each set. A set hence comprised four dropout vignettes and four typical competitor vignettes. The sets were randomly assigned to employers, who were presented the eight vignettes in a random order to prevent primacy and learning effects. Competitor vignettes in each set resembled dropout vignettes as closely as possible, except for the fact that competitors had no dropout experience. The 'mirror-design' enables us to precisely estimate differences in the ratings between dropouts and their competitors within each respondent, and thereby, to compute an average causal effect of HE non-completion on applicants' hiring chances. Naturally, some information is implausible for competitors. This is most obvious for typical competitors in the apprenticeship market, who apply straight out of upper secondary school. These applicants cannot have any information about GPA in university, length of study episode, or fit between field of study and the aspired occupation. Furthermore, upper secondary school leavers do not have time to complete a 3-month internship during school. In these cases, competitor vignettes simply have less information, which is ecologically valid: In real-life hiring situations, their CVs also convey less information to employers. We explain below how we considered this fact in our models and why this does not preclude causal inference.

\section{Analysis}

Hiring intentions are analyzed using multilevel regression models to account for the nested data structure (vignette ratings nested in employers). Our basic specifications include all vignette dimensions, and various covariates that may affect hiring chances, such as candidate queue, firm size, sector and occupational field (see Table 1 for details). To account for possible methodological effects, we further include vignette set and order as controls ( $\mathrm{Su}$ and Steiner 2020). 
To test the causal effect of HE non-completion on the hiring chances in different labor market segments (RQ1), we made dropout and competitor vignettes as comparable as possible by excluding certain vignettes from the analyses: For apprenticeship positions, we compare school leavers only with early dropouts (i.e., $2^{\text {nd }}$ semester) to minimize age differences. Furthermore, we excluded dropout vignettes that had completed an internship, as the upper secondary school competitors also had no internship. With these exclusions, we are able to answer the counterfactual question on what would have happened if a dropout simply had applied for an apprenticeship right away without trying to succeed in HE. Similarly, in the skilled worker market and the HE graduate market, we included only dropout vignettes with a long study episode (6 semesters). Because competitor vignettes in both markets had also been trained for 3 years ( 6 semesters), this restriction ruled out age differences and differences in training time. Thus, the only remaining difference pertained to the dropout experience. Appendix $\mathrm{H}$ in the online supplement shows that the exclusion of the mentioned vignettes does not substantially increase the correlations among vignette dimensions, and thereby, does not lead to confounded estimates. To estimate the impact of various characteristics within dropouts (RQ2), we included all dropout vignettes, but excluded the competitor vignettes, as we were only interested in variation within the dropout universe.

To account for missing data on both vignette ratings $(\leq 4.5 \%)$ and covariates (ranging between $0.1 \%$ and $27.3 \%$ ), we applied multiple imputation via chained equations. In the imputation model, we included all analyses variables and additional information on employers collected by the questionnaire and the real-world vacancies as auxiliary variables to increase precision of the imputed values. We generated and summarized $\mathrm{m}=10$ complete data sets according to Rubin's (1987) rules.

\section{Results}

We begin by estimating the overall hiring chances for dropouts vis-à-vis their typical competitors at the three entry ports, before we investigate factors that facilitate labor market entry for dropouts.

\section{The Effect of Dropping Out on the Hiring Chances in Different Labor Market Segments}

Table 3 reports the effects of HE non-completion on employers' hiring intentions in different labor market segments. Effects can be interpreted as percentage point differences in hiring 
probability between dropouts and otherwise identical competitors. ${ }^{9}$ In Model 1 , we examine hiring chances for apprenticeship positions. The results show no statistically significant differences $(\mathrm{B}=$ $0.85, \mathrm{SE}=0.59)$ between dropouts and applicants who are about to finish upper secondary school. Separate models for apprenticeships in IT and business reveal that employers have a slight preference for dropouts over upper secondary school leavers in IT $(\mathrm{B}=2.28, \mathrm{SE}=0.96)$, but not in business $(\mathrm{B}=-0.39, \mathrm{SE}=0.69$, see Appendix $\mathrm{J}$ in the online supplement). With an average hiring propensity of $58 \%$ for our vignettes in this labor market segment, these variations are substantively negligible. Taken together, these findings support $\mathrm{H} 1$ in showing that individuals who failed to complete HE are not disadvantaged when applying for apprenticeship positions visà-vis their typical competitors.

Table 3: Hiring Probabilities for Different Labor Market Segments

\begin{tabular}{|c|c|c|c|c|c|c|}
\hline \multirow[b]{2}{*}{ Dropout (vs. competitor) } & \multicolumn{2}{|c|}{$\begin{array}{c}\text { (1) } \\
\text { Apprenticeship } \\
\text { places }\end{array}$} & \multicolumn{2}{|c|}{$\begin{array}{c}\text { (2) } \\
\text { Skilled worker } \\
\text { positions }\end{array}$} & \multicolumn{2}{|c|}{$\begin{array}{c}(3) \\
\text { HE graduate } \\
\text { positions }\end{array}$} \\
\hline & 0.85 & $(0.59)$ & $-17.86^{* * *}$ & $(1.03)$ & $-25.22^{* * *}$ & $(0.78)$ \\
\hline GPA (upper sec. school) & $3.38^{* * *}$ & $(0.47)$ & $3.26^{* * *}$ & $(0.76)$ & $1.78^{*}$ & $(0.73)$ \\
\hline Candidate queue & $2.66^{* *}$ & $(0.96)$ & -0.35 & $(1.28)$ & 1.44 & $(1.49)$ \\
\hline \multicolumn{7}{|l|}{ Firm size $($ ref $=0-49)$} \\
\hline $50-499$ & $3.88^{* *}$ & $(1.41)$ & 2.25 & $(2.78)$ & 0.98 & $(2.68)$ \\
\hline$>=500$ & 2.83 & (1.79) & 1.97 & $(2.84)$ & 2.45 & $(3.18)$ \\
\hline \multicolumn{7}{|l|}{ Sector (ref $=$ industry) } \\
\hline Market services & -0.24 & $(2.30)$ & 0.83 & $(4.38)$ & 2.76 & $(3.27)$ \\
\hline Non-market services & -4.52 & $(2.90)$ & -2.98 & (4.93) & -1.04 & $(3.10)$ \\
\hline IT (vs. business job) & $-9.73^{* * *}$ & $(1.37)$ & 0.12 & $(2.00)$ & $14.17^{* * *}$ & $(2.06)$ \\
\hline Constant & $38.50^{* * *}$ & $(3.75)$ & $50.62^{* * *}$ & $(5.89)$ & $23.21^{* * *}$ & $(5.97)$ \\
\hline SD (employer) & $15.12^{* * *}$ & $(0.47)$ & $16.74^{* * *}$ & $(0.74)$ & $16.50^{* * *}$ & $(0.75)$ \\
\hline SD (vignette) & $12.96^{* * *}$ & $(0.18)$ & $15.76^{* * *}$ & $(0.32)$ & $15.81^{* * *}$ & $(0.29)$ \\
\hline $\mathrm{ICC}$ & \multicolumn{2}{|c|}{0.58} & \multicolumn{2}{|c|}{0.53} & \multicolumn{2}{|c|}{0.52} \\
\hline Log likelihood & \multicolumn{2}{|c|}{$-14,514.14$} & \multicolumn{2}{|c|}{$-9,180.92$} & \multicolumn{2}{|c|}{$-8,739.44$} \\
\hline$N$ Vignettes & \multicolumn{2}{|c|}{3,467} & \multicolumn{2}{|c|}{2,112} & \multicolumn{2}{|c|}{2,010} \\
\hline$N$ Employers & \multicolumn{2}{|c|}{695} & \multicolumn{2}{|c|}{352} & \multicolumn{2}{|c|}{335} \\
\hline
\end{tabular}

Note: Random-intercept models, standard errors in parentheses, controls: other vignette dimensions, vignette set and order, ${ }^{*} p<0.05,{ }^{* *} p<0.01,{ }^{* * *} p<0.001$.

Model 2 reports our findings for skilled jobs in the vocational segments of the labor market. As expected, dropouts are disadvantaged in the hiring process: Their hiring probability is on average 17.86 percentage points lower than that of applicants with a completed VET degree in the respective field. Similar to the apprenticeship market, hiring chances are slightly better for IT than for business jobs, but the difference is neither statistically nor substantively significant (Appendix 
I). Finally, model 3 shows the results for HE graduate positions. Individuals with incomplete HE are strongly disadvantaged: Their hiring probability is 25.22 percentage points lower than the hiring probability of HE graduates. Differences between IT and business are not significant (Appendix I). Therefore, we refrain from reporting differences between occupational fields from here on. In sum, $\mathrm{H} 2$ and $\mathrm{H} 3$ are supported. Otherwise identical applicants with a dropout experience have substantially lower hiring chances than their competitors without a dropout experience. To put these effects into context, table 3 also depicts the effect of academic performance (GPA) in upper secondary school. This is a typical signal sent in CVs capturing the things one has learned in school and the motivation to learn. A meta-analysis shows that school GPA is a good predictor of career success (Strenze 2007). It becomes evident that for skilled worker and $\mathrm{HE}$ graduate positions $\mathrm{HE}$ non-completion is a much stronger predictor of hiring chances than performance in school.

\section{Occupational Closure}

Because closure is common in the German labor market, we expect that (H4) disadvantages of dropouts in the skilled and graduate labor market are partly driven by occupational closure. To test this hypothesis, we included an interaction effect between non-completion and closure in the models estimating the hiring chances in both labor markets. Figure 3 depicts hiring chances, separated by firms that stated it is (vs. it is not) possible to fill the respective position with an applicant who does not fulfill the formal educational requirements. ${ }^{10}$ As expected, hiring chances for dropouts are much worse if firms required an educational certificate as an entry ticket to the job. Chances were reduced by 13.44 percentage points for skilled positions, and by 11.88 percentage points for HE graduate positions. 
Figure 3: Hiring Chances by Closure

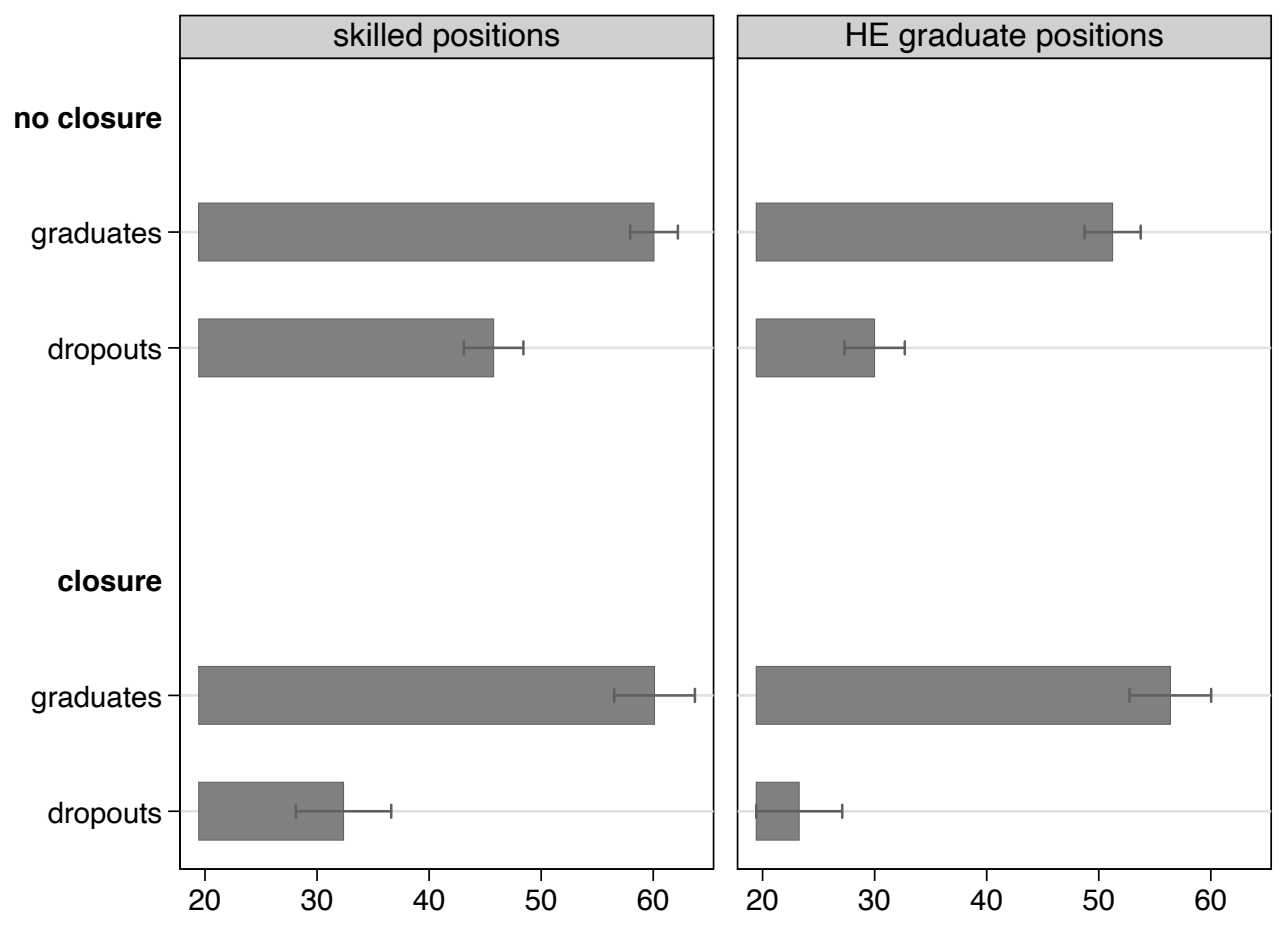

Note: Models include interaction effect of dropout * no_closure. Coef -13.44 (SE 2.11) for skilled worker pos.; Coef -11.88 (SE 1.63) for HE grad. pos. Closure based on item 'not possible to fill [POSITION] with someone who does not fulfill the formal educational requirements'. Model controls: other vignette dimensions, candidate queue, firm size, sector, occupational field, vignette set and order.

\section{Factors Facilitating Labor Market Entry for Dropouts}

Individuals with incomplete education have very different $\mathrm{HE}$ trajectories, which likely impact their labor market integration. To estimate the impact of various characteristics within dropouts (RQ2), we included all dropout vignettes, but excluded the competitor vignettes (four per employer), as we were only interested in variation within the dropout universe. In the skilled and graduate labor market, we also excluded employers who stated that in their firm it is not possible to hire non-degree holders for a skilled or graduate position, reducing the respective samples to 264 (skilled positions) and 222 (HE graduate positions) employers. Figure 4 summarizes our findings. Appendix $\mathrm{K}$ in the supplement contains the corresponding regression tables. 
Figure 4: Facilitators Among Dropouts for Different Labor Market Segments
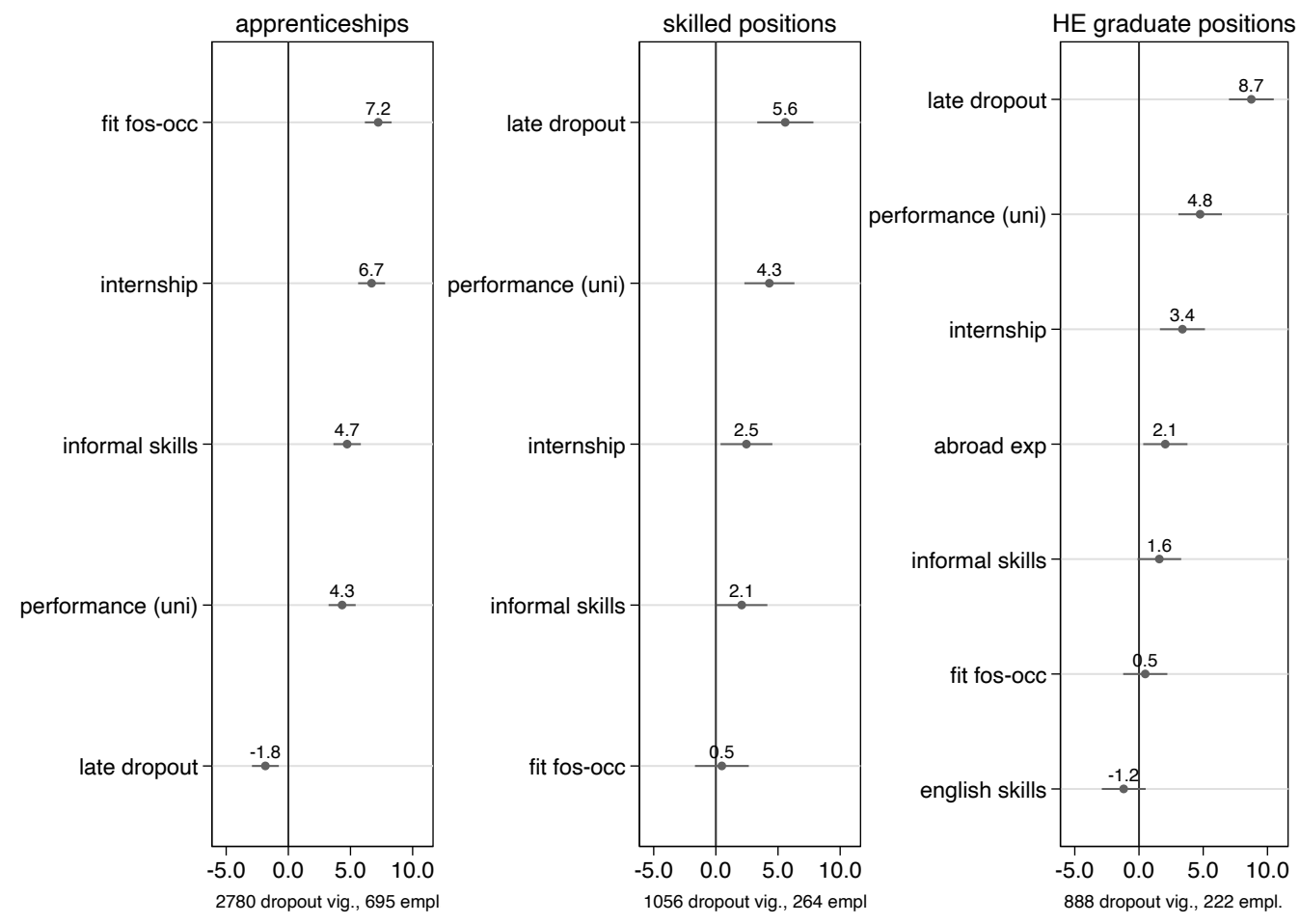

Note: controls: other vignette dimensions (e.g. GPA in upper secondary school), candidate queue, firm size, sector, occupational field, vignette set and order.

In line with H5, we find that a high grade point average, a job-related internship, and jobrelated informal skills increase the hiring chances of dropouts for all types of positions. In addition, and in agreement with H5, applicants for apprenticeship positions benefit strongly from applying for occupations that closely match the aborted field of study (e.g. non-completers of computer science studies applying for a position as computer science expert). Their hiring chances are 7.2 percentage points higher compared to dropouts from fields of study that reflect opposing vocational interests, such as teacher training or biology. Followed by internships (6.7 percentage points), fit between field of study and job tasks is the strongest 'facilitator' to increase hiring chances for apprenticeship positions. We cannot show this for skilled worker and HE graduate positions. Our pre-studies showed that applications with unmatching fields of study are highly uncommon and we therefore decided not to include them in our study. Instead, we varied "fit" on a much smaller range, with high fit indicating a fitting course specialization within a fitting study field (e.g. a former computer science student who specialized in system integration applying for a 
job specializing on system integration), and low fit indicating an unfitting course specialization (e.g. software development) within a fitting study field. This variation is non-significant.

As expected in H6, a longer study episode lowers the hiring chances for apprenticeships (by 1.8 percentage points), but raises the hiring chances for skilled and graduate positions (by 5.6 and 8.7 percentage points). In fact, a longer study episode is the strongest factor facilitating labor market entry on the skilled worker and the HE graduate market. The second strongest factor in the skilled and graduate job market is academic performance (GPA) during HE studies. The probability to get hired increases by about 4.5 percentage points, if a dropout has obtained good grades instead of bad grades. In line with $\mathrm{H} 7$, we find that abroad study experiences are valued by employers and increase hiring chances for dropouts applying for graduate positions, while proficient (vs. intermediate) English skills do not significantly alter employers' hiring intentions.

\section{Conclusion and Discussion}

What is the causal effect of dropping out on the hiring chances in different labor market segments, and which factors facilitate labor market entry for dropouts? We examined these questions in light of an unprecedented educational expansion which has led to millions of students worldwide who leave higher education without graduating. In contrast to earlier studies in the field, we assessed employers' hiring behavior directly, and compared dropouts' hiring chances in different labor market segments to those of otherwise identical persons, who aspired to the same occupations.

Focusing on Germany, our findings show that compared to upper secondary school leavers, university dropouts have equal hiring chances when applying for apprenticeship positions. Put differently, there is no penalty for trying and failing (Hällsten 2017), if dropouts apply for apprenticeships. This is theoretically intriguing, as it contradicts the widely cited educational decision model by Breen and Goldthorpe (1997), which assumes that trying and failing leads to a lower class status than not trying at all. This is important for educational inequality because working class students often opt for less ambitious educational careers to avoid the risk of failure. For Germany, however, our findings suggest there is no risk involved in choosing to enter HE, as the 'VET-safety net' receives HE non-completers with open arms. ${ }^{11}$ To mitigate inequalities, it would be important to convey this information to working class and other risk-averse students. 
The picture is quite different when those who have failed to complete HE apply for qualified positions in the job markets for skilled workers or HE graduates. Here, disadvantages are substantial, with obstacles being highest for positions where dropouts compete with HE graduates. This is true in firms that do not regard a formal degree as a requirement for hiring a candidate, but even more so in firms that close positions to non-degree holders. The relative importance of noncompletion becomes evident when comparing the effect to those of other signals typically sent in CVs, such as GPA in upper secondary school. Our findings are generally in line with previous 'supply-side' research showing that completed degrees are associated with higher job statuses and earnings (e.g. Flores-Lagunes and Light 2010; Heigle and Pfeiffer 2019). One important contribution of our analyses is to show that findings from these previous studies remain largely robust under experimental conditions. Furthermore, we can directly show that employers' hiring behavior plays a crucial role: Job status and earnings disadvantages emerge because employers function as gatekeepers who are - on average - less willing or able to hire individuals who did not complete HE (Di Stasio and van de Werfhorst 2016).

These findings make inroads into important theoretical discussions about how employers make decisions, and how a successful labor market integration of the large group of students with some college can be achieved. For instance, it is widely believed that hiring chances should depend on the quality of the competitors, as Thurow's (1975) queuing argument suggests. Because dropout candidates in our study apply for jobs in different labor market segments, where the quality of the competitors varies systematically, we can directly test this assumption and confirm that a specific signal, here, non-completion, leads to very different hiring chances conditional on the quality of the labor queue. More generally, our findings collectively point to the overwhelming importance of credentials for the hiring chances in strongly linked training regimes, such as Germany. A missing credential is harshly penalized, while additional years of schooling, as in the case of HE dropouts applying for apprenticeship positions, are of little value. Our findings also inform theoretical debates about credentialism and linkage-strength in school-to-work-transitions. A recent research agenda proposes that linkage strength varies within countries along granular educational levels and fields of study (DiPrete et al. 2017). Our findings regarding occupational closure add another layer of granularity, by showing that credentialist hiring, which contributes to linkage strength, varies between employers in the same country hiring for the same occupations (cf. Figure 3). To our knowledge, we are the first to directly measure occupational closure by 
educational credentials on the firm level, and to assess its impact for hiring chances of applicants who possess a credential - or not.

We believe our results to be relatively conservative, as we compared only dropouts that were as similar as possible to their competitors, providing a high internal validity to identify causal effects. In reality, when applying for HE graduate positions, dropouts often have fewer years of education and poorer academic performance than their competitors, so that disadvantages are probably even stronger. In contrast, individuals with incomplete education may have better hiring chances when applying for apprenticeship positions because, unlike school-leavers, they have often completed an internship which is an important facilitator in this labor market segment.

Individuals with incomplete tertiary education differ not only in the paths they seek to enter the labor market, but also with respect to other characteristics. Which of them increase hiring prospects? Unlike prior research, which has often treated dropouts as a dummy category, our vignette study enabled us to zoom in on their different characteristics. To the best of our knowledge, this is the first study that theorizes and assesses the effects of different signals that dropouts can send during the hiring process. Our findings confirm that such a nuanced approach is important for understanding the labor market consequences of $\mathrm{HE}$ non-completion, and that previous accounts are oversimplifications. As expected, we find that a high GPA, as well as signals of occupations-specific skills, such as a job-related internship, job-related informal skills, or a close match between field of study and the target occupation increase the hiring chances of dropouts for all types of positions. More time spent in university lowers the hiring chances for apprenticeships, but raises the hiring chances for skilled and graduate positions. Our explanation is that while employers seek young apprentices who can be more easily integrated into the social context of the work place, they refrain from offering skilled or graduate jobs to early dropouts, as these applicants cannot possess the required competencies. In addition, applicants for graduate positions benefit from an abroad experience, but not from proficient English skills. These nuanced findings are important for individuals facing withdrawal, and for HE institutions advising them.

We based our study in Germany, a country with a highly stratified and occupation-specific training system. This should increase the signaling capacity of degrees (Müller 2005), to the disadvantage of those without degrees. We conjecture that the results of this study may well extend to other European countries with similar systems, such as the Netherlands, Austria, or Switzerland. On the other hand, we would expect that non-completion is less penalized in countries were the 
signaling capacity of degrees is lower, and where linkages between degrees and occupations are weaker, such as the United States (Di Stasio and van de Werfhorst 2016). Future research should extend our study to investigate how HE dropouts fare in other contexts. Another avenue for further research is to investigate what HE completion - or the lack of it - actually conveys to employers: occupation-specific skills, general cognitive skills, or non-cognitive skills.

This study has limitations. Besides applying for job advertisements, which is the most common and successful strategy to gain employment (Heublein et al. 2017), dropouts acquire jobs informally via social networks, which we cannot assess. Furthermore, we did not incorporate female or racial/ethnic minority vignettes for the sake of simplicity, and because a broad literature has examined gender and racial/ethnic hiring discrimination (for a review see Baert 2018). Nevertheless, future research would do well to assess whether dropouts from traditionally disadvantaged groups are evaluated differently than white male applicants. Recent work suggests that negatively stereotyped categories can interact in various ways (Pedulla 2018), therefore, the signal of non-completion may vary across racial/ethnic groups, or gender identities. For example, an incomplete HE episode could amplify existing disadvantages of ethnic minorities in the labor market. Additionally, we focused on two occupational fields (IT and business) that are in high demand by employers of various firms, to obtain a relatively diverse sample. Nevertheless, we cannot generalize our results to other occupational fields. For instance, individuals with incomplete HE may be even more disadvantaged in fields that have less labor shortage, such as in the humanities. Likewise, they may be more disadvantaged in fields with higher degrees of occupational closure, such as in the natural sciences. Future research should consider a set of indicators that are distinctive for an occupational field and may affect hiring processes when addressing questions of whether dropouts' hiring chances differ across occupational fields. Lastly, this study targeted only labor market entrants. While the initial hiring decision is obviously important, dropouts may be able to advance in their career faster than high school completers or close the gap with college graduates over time if their university experience allowed them to acquire skills that are valuable in their careers, in line with human capital theory. How labor market prospects of dropouts develop over the course of their careers are interesting avenues for future research.

Despite these limitations, we believe that a main contribution of this article is to provide detailed and experimentally controlled knowledge on the consequences of unsuccessfully 
attempted qualifications, as opposed to successfully completed degrees, for which our knowledgebase is much broader. Another important contribution is that we provide evidence on factors that mitigate the negative consequences of non-completed education. Importantly, we complement supply-side studies with a demand-side perspective. This is theoretically intriguing because theories of job assignment suggest that employers give a lot of weight to achieved educational credentials. From a more practical perspective, our findings can help to inform students and career counselling, because they provide evidence on how to optimize labor market entries in case of an imminent dropout. For instance, students contemplating to withdraw should be supported in their effort for good grades as these increase hiring prospects. Similarly, they should be advised to complete a job-related internship to increase their hiring chances. They should also be informed about the very different hiring success probabilities associated with the three paths into employment. 


\section{Endnotes}

${ }^{1}$ In Germany, about 500,000 young adults enroll in HE institutions each year (Federal Statistical Office 2020). With an estimated dropout rate of $30 \%$ this totals to 150,000 dropouts annually.

${ }^{2}$ Other dropouts become self-employed, or they get jobs via social networks (e.g. friends, parents, or employers they had worked for prior to their studies). Heublein et al. (2017), however, show that the most common and successful labor market entry strategy is to apply for job offers.

${ }^{3}$ Note, however, that hiring differences do not necessarily disprove human capital theory, if the more knowledgeable ones complete education, or if the last stretch to receive a degree leads to a boost in skill acquisition (Flores-Lagunes and Light 2010).

${ }^{4}$ For example, Di Stasio and van de Werfhorst (2016) sampled 72 employers, Damelang et al. (2020) sampled 394 employers. Our response rate is within the range of these and other studies among employers (Baruch and Holtom 2008).

${ }^{5}$ Among all interview partners, there were nine experts on the apprenticeship market, seven experts on the skilled worker market, six experts on the HE graduate market, and three experts familiar with recruitment processes in all three entry ports.

${ }^{6}$ Compared to the U.S., the grading system in Germany is reversed, with 1 being the best and 6 being the worst possible mark.

${ }^{7}$ Even though dropouts applying for apprenticeships and skilled worker positions may similarly have acquired proficient English skills and gained abroad experiences, we did not vary these dimensions here. Neither the literature nor the pre-study interviews with employers indicated these to be relevant dimensions in hiring decisions in these labor market segments.

${ }^{8}$ Nevertheless, we checked whether these photos affect vignettes' evaluation, but we did not find any effect on our dependent variables.

${ }^{9}$ Some may argue that hiring is preceded by inviting an applicant to a job interview. Repeating our analysis with a dependent variable that asks employers to indicate how likely they would invite a candidate to a job interview (instead of hiring him) lead to similar findings (see Appendix I in the online supplement).

${ }^{10}$ In our sample, about one third of the firms fall into the closure category (see table 2). We use the community-contributed software MIMRGNS (Klein 2014) to obtain predicted values in multiply-imputed datasets, and COEFPLOT (Jann 2014) to create the figures.

${ }^{11}$ As there is no tuition fee in Germany, the only cost is forgone earnings while being enrolled, but the risk of marginalization that diverts working class students does not seem to exist. 


\section{References}

Allmendinger, Jutta. 1989. "Educational Systems and Labor Market Outcomes.” European Sociological Review 5(3):231-250.

Arrow, Kenneth J. 1973. "Higher Education as a Filter." Journal of Public Economics 2:193-216.

Auspurg, Katrin, and Thomas Hinz. 2015. Factorial Survey Experiments. London: SAGE.

Baert, Stijn. 2018. "Hiring discrimination: An overview of (almost) all correspondence experiments since 2005" In Audit studies: Behind the Scenes with Theory, Method, and Nuance, edited by S. Michael Gaddis, 63-77, Cham: Springer.

Baert, Stijn, and Matteo Picchio. 2021. “A Signal of (Train)Ability? Grade Repetition and Hiring Chances.” Journal of Economic Behavior \& Organization 188: 867-878.

Baruch, Yehuda, and Brooks C. Holtom. 2008. Survey Response Rate Levels and Trends in Organizational Research. Human Relations 61:1139-1160.

Becker, Gary S. 1964. Human Capital. A Theoretical and Empirical Analysis with Special Reference to Education. New York: Columbia University Press.

BIBB = Bundesinstitut für Berufsbildung. 2020. Datenreport zum Berufsbildungsbericht. Informationen und Analysen zur Entwicklung der beruflichen Bildung. Bonn: BIBB.

Bills, David B. 1988. "Educational Credentials and Hiring Decisions: What Employers Look for in New Employees.” Research in Social Stratification and Mobility 7:71-97.

Bills, David B. 2003. "Credentials, Signals, and Screens: Explaining the Relationship between Schooling and Job Assignment." Review of Educational Research 73:441469.

Bills, David B., Valentina Di Stasio, and Klarita Gërxhani. 2017. "The Demand Side of Hiring: Employers in the Labor Market.” Annual Review of Sociology 43:291-310.

Blossfeld, Hans-Peter. 1987. "Labor-Market Entry and the Sexual Segregation of Careers in the Federal Republic of Germany." American Journal of Sociology 93(1):89-118.

Bol, Thijs, and Herman G. Van de Werfhorst. 2011. "Signals and Closure by Degrees: The Education Effect across 15 European Countries." Research in Social Stratification and Mobility 29(1):119-132.

Bol, Thijs, and Kim A. Weeden. 2015. "Occupational Closure and Wage Inequality in Germany and the United Kingdom. European Sociological Review 31(3):354-369. 
Bowen, William G., Matthew M. Chingos, and Michael S. McPherson. 2009. Crossing the Finish Line: Completing College at America's Public Universities. Princeton University Press.

Breen, Richard, and John H. Goldthorpe. 1997. "Explaining Educational Differentials: Towards a Formal Rational Action Theory.” Rationality and Society 9(3):275-305.

Damelang, Andreas, Sabine Ebensperger, and Felix Stumpf. 2020. "Foreign Credential Recognition and Immigrants' Chances of Being Hired for Skilled Jobs-Evidence from a Survey Experiment Among Employers.” Social Forces, https://oi.org/10.1093/sf/soz154.

Daniel, Annabell, Martin Neugebauer, and Rainer Watermann. 2019. "Studienabbruch und Einstellungschancen auf dem Ausbildungsmarkt. Ein faktorieller Survey mit Arbeitgeber/innen.“ Zeitschrift für Erziehungswissenschaft 22(5):1147-1174.

Davies, Rhys, and Peter Elias. 2003. Dropping Out: A Study of Early Leavers from Higher Education (Research Report RR386). London: Department for Education and Science.

Deterding, Nicole M., and David S. Pedulla. 2016. "Educational Authority in the 'Open Door' Marketplace: Labor Market Consequences of For-profit, Nonprofit, and Fictional Educational Credentials." Sociology of Education 89(3):155-170.

DiPrete, Thomas A., Christina C. Eller, Thijs Bol, and Herman G. Van de Werfhorst. 2017. "School-to-Work Linkages in the United States, Germany, and France." American Journal of Sociology 122(6):1869-1938.

Di Stasio, Valentina. 2014. "Education as a Signal of Trainability: Results from a Vignette Study with Italian Employers.” European Sociological Review 30(6):796-809.

Di Stasio, Valentina, and Herman G. Van de Werfhorst. 2016. "Why Does Education Matter to Employers in Different Institutional Contexts? A Vignette Study in England and the Netherlands." Social Forces 95(1):77-106.

Dülmer, Hermann. 2016. "The Factorial Survey: Design Selection and its Impact On Reliability and Internal Validity." Sociological Methods \& Research 45(2):304-347. Federal Statistical Office (2020). First-year students by area of study. Retrieved from https://www.destatis.de/DE/Themen/Gesellschaft-Umwelt/Bildung-Forschung$\underline{\text { Kultur/Hochschulen/Tabellen/studierende-erstes-hs- }}$ faechergruppen.html?view=main[Print]. Accessed August 05, 2020. 
Flores-Lagunes, Alfonso, and Audrey Light. 2010. "Interpreting Degree Effects in the Returns to Education.” Journal of Human Resources 45(2):439-467.

Giani, Matt S., Paul Attewell, and David Walling. 2020. "The Value of an Incomplete Degree: Heterogeneity in the Labor Market Benefits of College Non-Completion.” The Journal of Higher Education 91(4):514-539.

Ghignoni, Emanuela, Giuseppe Croce, and Alessandro d'Ambrosio. 2019. "University Dropouts vs High School Graduates in the School-to-Work Transition: Who is doing Better?” International Journal of Manpower 40(3):449-472.

Grubb, W. Norton. 2002. "Learning and Earning in the Middle, Part I: National Studies of Pre-baccalaureate Education." Economics of Education Review 21:299-321.

Hällsten, Martin. 2017. "Is Education a Risky Investment? The Scarring Effect of University Dropout in Sweden.” European Sociological Review 33(2):169-181.

Hainmueller, Jens, Dominik Hangartner, and Teppei Yamamoto. 2015. "Validating Vignette and Conjoint Survey Experiments against Real-World Behavior." Proceedings of the National Academy of Sciences 112:2395-2400.

Haupt, Andreas. 2016. Zugang zu Berufen und Lohnungleichheit in Deutschland. Wiesbaden: Springer VS.

Heigle, Julia, and Friedhelm Pfeiffer. 2019. An Analysis of Selected Labor Market Outcomes of College Dropouts in Germany: A Machine Learning Estimation Approach (Research Report). Mannheim: ZEW-Centre for European Economic Research.

Heublein, Ulrich, Julia Ebert, Christopher Hutzsch, Sören Isleib, Richard König, Johanna Richter, and Andreas Woisch. 2017. Zwischen Studienerwartungen und Studienwirklichkeit. Forum Hochschule, 1/2017. Hannover: DZHW.

Humburg, Martin, and Rolf Van der Velden. 2015. "Skills and the Graduate Recruitment Process: Evidence from Two Discrete Choice Experiments.” Economics of Education Review 49:24-41.

Hungerford, Thomas, and Gary Solon. 1987. "Sheepskin Effects in the Returns to Education." The Review of Economics and Statistics 69(1):175-177.

Imdorf, Christian. 2012. Zu jung oder zu alt für eine Lehre? Altersdiskriminierung bei der Ausbildungsplatzvergabe. Journal for Labour Market Research 45:79-98. 
Jackson, Michelle. 2007. "How Far Merit Selection? Social Stratification and the Labour Market." The British Journal of Sociology 58(3):367-390.

Jacob, Marita, Michael Kühhirt, and Margarida Rodrigues. 2019. "Labour Market Returns to Graduates' International Experience: Exploring Cross-Country Variation in Europe.” European Sociological Review 35(4):491-505.

Jann, Ben. 2014. "Plotting Regression Coefficients and other Estimates." The Stata Journal $14: 708-737$.

Johnes, Jill, and Jim Taylor. 1991. "Non-Completion of a Degree Course and its Effect on the Subsequent Experience of Non-Completers in the Labour Market." Studies in Higher Education 16(1):73-81.

Jovanovic, Boyan. 1979. "Job Matching and the Theory of Turnover." Journal of Political Economy 87(5):972-990.

Kane, Thomas J., and Cecilia Elena Rouse. 1995. "Labor-Market Returns to Two-and FourYear College." The American Economic Review 85(3):600-614.

Klein, Daniel. 2014. MIMRGNS: Stata Module to Run Margins After Mi Estimate. Boston College Department of Economics: Statistical Software Components. Available at: https://ideas.repec.org/c/boc/bocode/S457795.html. Accessed August 25, 2020.

Leuze, Kathrin. 2007. "What Makes for a Good Start? Consequences of OccupationSpecific Higher Education for Career Mobility: Germany and Great Britain Compared." International Journal of Sociology 37(2):29-53.

Light, Audrey, and Wayne Strayer. 2004. "Who Receives the College Wage Premium? Assessing the Labor Market Returns to Degrees and College Transfer Patterns." The Journal of Human Resources 39(3):746-773.

Ma, Debbie S., Joshua Correll, and Bernd Wittenbrink. 2015. "The Chicago Face Database: A Free Stimulus Set of Faces and Norming Data." Behavior Research Methods 47(4):1122-1135.

Mai, Quan D. 2021. "Unclear Signals, Uncertain Prospects: The Labor Market Consequences of Freelancing in the New Economy." Social Forces 99(3):895-920.

Marsden, David. 1990. "Institutions and Labour Mobility: Occupational and Internal Labour Markets in Britain, France, Italy and West Germany.” In Labour Relations 
and Economic Performance, edited by Renato Brunetta and Carlo Dell'Aringa, 414438. London: Palgrave Macmillan.

Matković, Teo, and Irena Kogan. 2012. "All or Nothing? The Consequences of Tertiary Education Non-Completion in Croatia and Serbia." European Sociological Review 28(6):755-770.

Müller, Walter. 2005. "Education and Youth Integration into European Labour Markets." International Journal of Comparative Sociology 46(5-6):461-485.

Neugebauer, Martin, Ulrich Heublein, and Annabell Daniel. 2019. "Studienabbruch in Deutschland: Ausmaß, Ursachen, Folgen, Präventionsmöglichkeiten." Zeitschrift für Erziehungswissenschaft 22(5):1025-1046.

OECD. 2013. Education at a Glance 2013: OECD Indicators. Paris: OECD.

OECD. 2019. Education at a Glance 2019: OECD Indicators. Paris: OECD.

Pedulla, David S. 2018. "How Race and Unemployment Shape Labor Market Opportunities: Additive, Amplified, or Muted Effects?" Social Forces 96(4):1477-1506.

Pedulla, David S. 2016. "Penalized or Protected? Gender and the Consequences of Nonstandard and Mismatched Employment Histories." American Sociological Review 81(2):262-289.

Petzold, Knut, and Tobias Wolbring. 2019. "What Can We Learn from Factorial Surveys About Human Behavior?" Methodology 15:19-30.

Piopiunik, Marc, Guido Schwerdt, Lisa Simon, and Ludger Woessmann. 2020. "Skills, Signals, and Employability: An Experimental Investigation." European Economic Review 123:103374.

Quadlin, Natasha. 2018. "The Mark of a Woman's Record: Gender and Academic Performance in Hiring." American Sociological Review 83(2):331-360.

Rivera, Lauren A. 2020. Employer Decision Making. Annual Review of Sociology 46:215232.

Rosenbaum, James, Caitlin Ahearn, Kelly Becker, and Janet Rosenbaum. 2015. The New Forgotten Half and Research Directions to Support Them. New York, NY: William T. Grant Foundation. http://wtgrantfoundation.org/library/uploads/2015/09/TheNew-Forgotten-Half-and-Research-Directions-to-Support-Them.pdf.

Rubin, Donald B. 1987. Multiple Imputation for Nonresponse in Surveys. New York: Wiley. 
Schneider, Mark, and Lu Yin. 2011. The High Cost of Low Graduation Rates: How Much Does Dropping Out of College Really Cost? Washington, D.C.: American Institutes for Research.

Schnepf, Sylke V. 2017. "How Do Tertiary Dropouts Fare in the Labour Market? A Comparison between EU Countries." Higher Education Quarterly 71(1):75-96.

Scholten, Mirte, and Nicole Tieben. 2017. "Vocational Qualification as Safety Net? Education to Work Transitions of Higher Education Dropouts in Germany." Empirical Research in Vocational Education and Training 9(1):1-17.

Shavit, Yossi, and Walter Müller. 1998. From School to Work. A Comparative Study of Educational Qualifications and Occupational Destinations. Oxford: Oxford University Press.

Shi, Lulu P., and Senhu Wang. 2021. "Demand-Side Consequences of Unemployment and Horizontal Skill Mismatches across National Contexts: An Employer-Based Factorial Survey Experiment." Social Science Research, published ahead of print, https://doi.org/10.1016/j.ssresearch.2021.102668.

Spence, Michael. 1973. "Job Market Signaling." The Quarterly Journal of Economics 87:355-374.

Solga, Heike, Paula Protsch, Christian Ebner, and Christian Brzinsky-Fay. 2014. The German Vocational Education and Training System: Its Institutional Configuration, Strengths, and Challenges. WZB Discussion Paper SP1 2014-502.

Strenze, Tarmo. 2007. "Intelligence and Socioeconomic Success: A Meta-analytic Review of Longitudinal Research." Intelligence 35:401-426.

$\mathrm{Su}$, Dan, and Peter M. Steiner. 2020. "An Evaluation of Experimental Designs for Constructing Vignette Sets in Factorial Surveys." Sociological Methods \& Research 49(2):455-497.

Thurow, Lester C. 1975. Generating Inequality: Mechanisms of Distribution in the US Economy. New York: Basic Book.

Van de Werfhorst, Herman G. 2011. "Skills, Positional Good or Social Closure? The Role of Education Across Structural-Institutional Labour Market Settings." Journal of Education and Work 24(5):521-548. 
Weeden, Kim A. 2002. "Why Do Some Occupations Pay More Than Others? Social Closure and Earnings Inequality in the United States.” American Journal of Sociology 108(1):55-101.

Weisshaar, Katherine. 2018. "From Opt Out to Blocked Out: The Challenges for Labor Market Re-entry after Family-Related Employment Lapses.” American Sociological Review 83(1): $34-60$. 


\section{Appendix}

\section{Appendix A: Job titles (ISCO-08) for which the hiring was made}

\begin{tabular}{|c|c|c|c|}
\hline & apprenticeship positions & skilled worker positions & HE graduate positions \\
\hline IT & $\begin{array}{l}2514 \text { - computer science } \\
\text { expert (subject area: } \\
\text { software development) } \\
3513 \text { - computer science } \\
\text { expert (subject area: system } \\
\text { integration) }\end{array}$ & $\begin{array}{l}2514 \text { - computer science } \\
\text { expert (subject area: } \\
\text { software development) } \\
3513 \text { - computer science } \\
\text { expert (subject area: system } \\
\text { integration) }\end{array}$ & $\begin{array}{l}2511 \text { - computer scientist } \\
\text { (HE degree) with a focus on } \\
\text { system integration } \\
2512 \text { - computer scientist } \\
\text { (HE degree) with a focus on } \\
\text { software development }\end{array}$ \\
\hline business & $\begin{array}{l}4312 \text { - management } \\
\text { assistant for insurance and } \\
\text { finance (subject area: } \\
\text { financial consulting or } \\
\text { insurance) } \\
4211 \text { - banking professional } \\
3334 \text { - real estate } \\
\text { management assistant }\end{array}$ & $\begin{array}{l}4312 \text { - management } \\
\text { assistant for insurance and } \\
\text { finance (subject Area: } \\
\text { financial consulting or } \\
\text { insurance) } \\
4211 \text { - banking professional }\end{array}$ & $\begin{array}{l}2412 \text { - fund manager, } \\
\text { portfolio manager, } \\
\text { investment advisor, } \\
\text { underwriter, } \\
2411 \text { - controller, financial } \\
\text { analyst, insurance } \\
\text { operations manager }\end{array}$ \\
\hline
\end{tabular}




\section{Appendix B: Comparison of respondents and non-respondents}

Since we collected not only employers' e-mail address, but also further information from the vacancies sampled, we were able to check whether our sample of respondents differs from employers who were invited but did not participate in the survey. Marginal distributions of the gender of the contact person, firm size, occupational field, economic sector, and region largely correspond between respondents and non-respondents. Women responsible for hiring apprentices have a higher participation rate. Smaller firms are slightly underrepresented for apprenticeship positions, and overrepresented for HE graduate positions. Employers offering IT positions (as opposed to business positions) are less likely to participate in the apprenticeship study, but more likely to participate in the 'skilled worker'- and the 'HE graduate'- study. A stepwise inclusion of these characteristics as covariates in the models does not change our substantive findings.

\begin{tabular}{|c|c|c|c|c|c|c|}
\hline & \multicolumn{2}{|c|}{ apprenticeship positions } & \multicolumn{2}{|c|}{ skilled worker positions } & \multicolumn{2}{|c|}{ HE graduate positions } \\
\hline & $\begin{array}{l}\text { non-resp. } \\
(N=3310)\end{array}$ & $\begin{array}{c}\text { resp. } \\
(N=695)\end{array}$ & $\begin{array}{l}\text { non-resp. } \\
(N=3648)\end{array}$ & $\begin{array}{c}\text { resp. } \\
(N=352)\end{array}$ & $\begin{array}{l}\text { non-resp. } \\
(N=3669)\end{array}$ & $\begin{array}{c}\text { resp. } \\
(N=335)\end{array}$ \\
\hline \multicolumn{7}{|l|}{ employer characteristics - \% } \\
\hline female & 50.26 & 54.49 & 49.27 & 47.79 & 62.37 & 62.42 \\
\hline \multicolumn{7}{|l|}{ firm characteristics - \% } \\
\hline \multicolumn{7}{|l|}{ firm size } \\
\hline 0-49 employees & 35.82 & 30.35 & 44.49 & 49.79 & 34.29 & 46.59 \\
\hline 50-499 employees & 47.07 & 48.23 & 46.23 & 42.74 & 46.72 & 40.34 \\
\hline$\geq 500$ employees & 17.11 & 21.42 & 9.29 & 7.47 & 18.99 & 13.07 \\
\hline IT jobs (vs. business jobs) & 51.09 & 45.04 & 49.26 & 57.67 & 49.58 & 54.03 \\
\hline \multicolumn{7}{|l|}{ sector } \\
\hline industry & 12.25 & 9.29 & 4.73 & 7.52 & 10.36 & 11.29 \\
\hline market services & 80.82 & 82.15 & 89.21 & 85.29 & 75.53 & 77.82 \\
\hline non-market services & 6.93 & 8.55 & 6.06 & 7.19 & 14.11 & 10.89 \\
\hline \multicolumn{7}{|l|}{ based in (population) } \\
\hline rural community $(<5,000)$ & 7.78 & 7.13 & 4.93 & 4.60 & 3.48 & 1.94 \\
\hline small town $(5,000-19,999)$ & 22.60 & 23.29 & 14.83 & 16.95 & 11.53 & 14.19 \\
\hline $\begin{array}{l}\text { medium sized town }(20,000- \\
99,999)\end{array}$ & 34.31 & 32.61 & 26.89 & 25.57 & 21.19 & 23.87 \\
\hline big city $(>100,000)$ & 35.32 & 36.97 & 53.35 & 52.87 & 63.80 & 60.00 \\
\hline $\begin{array}{l}\text { Former territory of the } \\
\text { Federal Republic (vs. New } \\
\text { Länder and Berlin) }\end{array}$ & 87.16 & 86.09 & 81.03 & 81.53 & 83.12 & 80.06 \\
\hline
\end{tabular}




\section{Appendix C: Priming - Exemplary job offer for HE graduate positions (IT)}

We are looking for a computer scientist with a focus on software development

Your responsibilities:

- algorithmize problems und conceptualize software-solutions

- apply methods of software-engineering

- implement complex software-projects from requirement analysis to testing and document finished software applications

Our requirements:

- bachelor's degree in computer science or comparable qualification

- profound programming experience (Java, Python, $\mathrm{C}++$ )

- comprehensive knowledge in software development

- self-initiative and working independently

- capacity for teamwork to complete your profile

You find yourselve in this profile? We are looking forward to your application!

Note: To increase the external validity of the experiment, employers were prompted with a hypothetical job offer for exactly the occupation, for which they had recently advertised a vacancy themselves. The job offer comprised both a job description and job requirements which were based on the results of a qualitative content analysis of twenty randomly selected real-world vacancies for each occupation. 


\section{Appendix D: Description of additional characteristics}

Dimensions and levels of the fictitious CVs were designed on the basis of theoretical considerations, as well as three pre-studies in which we a) reviewed real applications and conducted 13 qualitative interviews with employers, b) tested the dimensions in a convenience sample of 733 students, and c) verified and adjusted our dimensions after conducting 12 cognitive interviews with employers.

To increase the external validity and to prevent fatigue effects when employers had to evaluate multiple vignettes, we varied additional characteristics that also differ in real-life hiring situations, and that are typically conveyed in real-life CVs.

(1) Academic performance (GPA) in school was varied by the grade values that mark the first and third quartile of the empirical distribution of upper secondary school leavers in Germany (KMK 2016). A GPA of 1.7 indicated a good academic performance, while a GPA of 3.3 described a bad academic performance.

(2) We also varied grades in German when applying for apprenticeships because our pretests revealed, in line with previous studies, that grades in the core academic subjects are important selection criteria in this labor market segment (e.g. Kübler et al. 2015). Thresholds for the grades were defined referring to the cut-off values reported by Protsch and Solga (2015), whereby $2+$ indicates a good and 3-indicates a bad academic performance in German.

(3) Grades in math were varied analogous to the German grades (9).

(4) Hobbies were varied by two levels, namely individual or team sports. For individual sports, we alternately used swimming and cycling, while for team sports handball and basketball were permuted in order to provide variety when evaluating eight vignettes. Swimming and cycling on the one hand and handball and basketball on the other hand were rated equal in terms of sportsman's' risk-taking propensity and capacity for teamwork in our pre-study.

(5) First names are connoted with social background, as one of our pre-studies showed, and may thus evoke reactions that could influence the evaluation of applicants. To keep those influences under control, we selected German first names which were associated either with lower class or middle class. Lower class names comprised 'Justin', 'Kevin', 'Pascal' and 'Steven', whereas 'Jakob', 'Felix', 'Konstantin' and 'Julius' represented middle class names. Applicants' last name was randomly sampled from a list of the 100 most common family names in Germany. 


\section{Appendix E: Example vignettes}

In the main text, we show an example vignette for the HE graduate market. Here we depict additional vignettes for the apprenticeship and the skilled worker market.

Figure S1: Example Vignette (Apprenticeship positions)

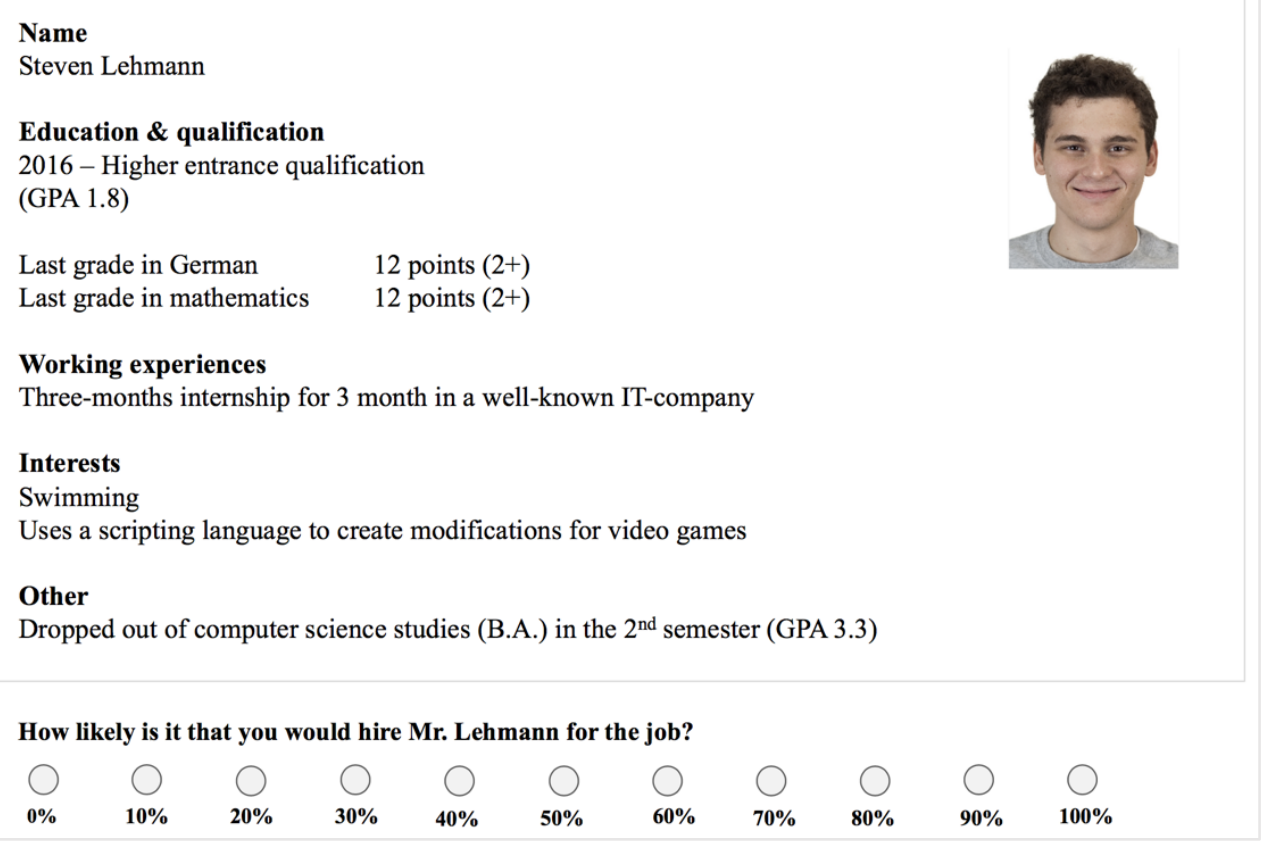

Figure S2: Example Vignette (Skilled worker positions)

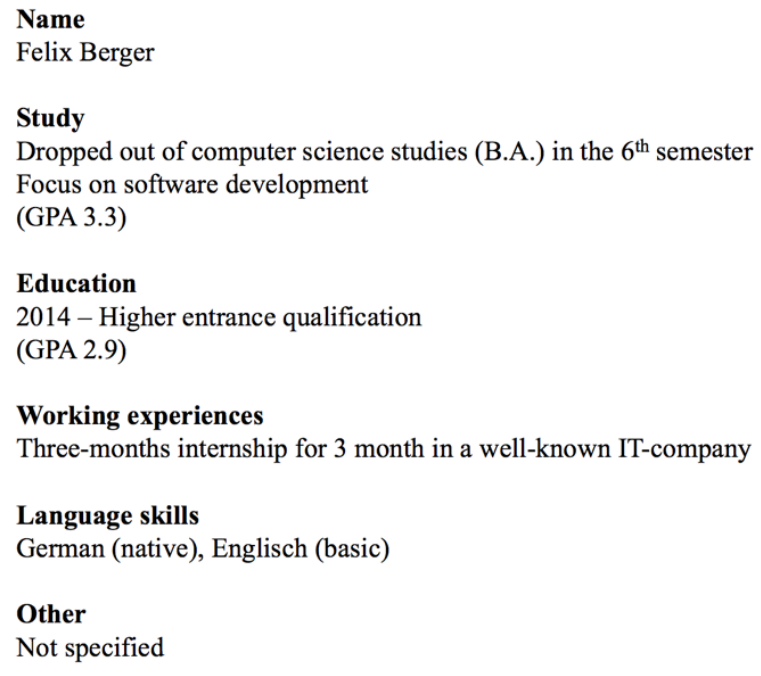




\section{Appendix F: Fractional factorial design}

Crossing all possible vignette dimensions results in vignette universes of a) 1024 vignettes for apprenticeship positions, b) 128 vignettes for skilled worker positions and c) 512 vignettes for HE graduate positions. As the number of vignettes to be judged by an individual respondent has to be restricted, we drew a fraction of 64 vignettes for each labor market segment. This fraction was primarily defined by the size and the number of sets. We chose a set size of four vignettes as they can be judged by each respondent without getting tired. Even when the set size doubles from four to eight vignettes by adding similar vignettes of competitors, respondents are able to judge the vignettes without getting frustrated over the repetitive task. Second, to estimate all main and twoway interaction effects without any confounding, the set size should be a whole multiple of all possible combinations of vignette dimensions. Since each dimension has only two levels, this would have been the case for four, but also eight non-completer vignettes. The latter, however, increases to a total of 16 vignettes when doubling the design by adding the competitor vignettes, and would likely cause fatigue effects. Thus, we chose a set size of four non-completer vignettes. The number of sets was determined by the expected sample size at the time of planning the design. Assuming a conservative response rate of five percent per labor market segment $(\mathrm{n}=100)$ and on the condition that each set should be judged by at least five respondents, 20 sets would have been the maximum. However, to obtain a balanced experimental design, the vignette universe for each labor market segment should be divisible accurately by the number of sets. As this was true for only 16 sets, we drew a fraction of 16 sets $\mathrm{x} 4$ vignettes $=64$ vignettes. 


\section{Appendix G: Pairwise correlations between vignette dimensions by labor market segment (dropout vignettes only)}

\begin{tabular}{|c|c|c|c|c|c|c|c|c|c|c|}
\hline A. & Apprenticeship p & ons & & & & & & & & \\
\hline & & $(2)$ & (3) & (4) & (5) & (6) & (7) & (8) & (9) & (10) \\
\hline (1) & gpa university & -.01 & -.01 & .00 & .00 & .01 & .00 & -.03 & .01 & .01 \\
\hline (2) & dropout time point & - & -.01 & .00 & .02 & .00 & -.02 & -.01 & .02 & .03 \\
\hline (3) & internship & & - & -.01 & .00 & -.01 & -.02 & -.03 & -.03 & .00 \\
\hline (4) & informal skills & & & - & .01 & .00 & .00 & .00 & -.01 & .00 \\
\hline (5) & fit bet. fos and job & & & & - & .01 & .02 & .01 & -.03 & -.02 \\
\hline (6) & gpa in school & & & & & - & -.01 & .00 & .00 & -.01 \\
\hline (7) & last grade German & & & & & & - & .00 & .00 & .00 \\
\hline (8) & last grade math & & & & & & & - & .00 & .01 \\
\hline (9) & sport hobby & & & & & & & & - & -.02 \\
\hline (10) & first name & & & & & & & & & - \\
\hline
\end{tabular}

\section{B. Skilled worker positions}

\begin{tabular}{|c|c|c|c|c|c|c|c|}
\hline & & (2) & (3) & (4) & (5) & (6) & (7) \\
\hline (1) & gpa university & .03 & -.01 & -.01 & .00 & .02 & .01 \\
\hline (2) & dropout time point & - & .02 & .00 & -.01 & .00 & .00 \\
\hline (3) & internship & & - & -.02 & -.02 & -.01 & .00 \\
\hline (4) & informal skills & & & - & -.01 & .02 & -.01 \\
\hline (5) & fit bet. fos and job & & & & - & .03 & -.01 \\
\hline (6) & gpa in school & & & & & - & .00 \\
\hline (7) & first name & & & & & & - \\
\hline
\end{tabular}

C. HE graduate positions

\begin{tabular}{|c|c|c|c|c|c|c|c|c|}
\hline & & $(2)$ & $(3)$ & (4) & (5) & $(6)$ & $(7)$ & (8) \\
\hline (1) & gpa university & -.02 & -.01 & .01 & -.03 & -.02 & .00 & .01 \\
\hline (2) & dropout time point & - & .02 & .00 & .00 & .02 & .01 & -.01 \\
\hline (3) & internship & & - & -.01 & .01 & .01 & -.01 & .00 \\
\hline (4) & informal skills & & & - & .04 & -.01 & -.01 & .00 \\
\hline (5) & fit bet. fos and job & & & & - & -.01 & -.01 & .00 \\
\hline (6) & English skills & & & & & - & -.01 & .01 \\
\hline (7) & abroad experience & & & & & & - & .02 \\
\hline (8) & first name & & & & & & & - \\
\hline
\end{tabular}




\section{Appendix H: Pairwise correlations between vignette dimensions by labor market segment (reduced design for RQ1 - dropout and competitor vignettes)}

\begin{tabular}{lrrrrrr}
\hline A. Apprenticeship positions $(N=3467$ vignettes $)$ \\
\hline \multicolumn{1}{l}{ (1) dropout } & $(2)$ & $(3)$ & $(4)$ & $(5)$ & $(6)$ & $(7)$ \\
(2) gpa school & -.01 & .01 & -.01 & .02 & -.01 & .00 \\
(3) last grade German & - & .01 & .00 & .05 & .00 & $\mathbf{. 0 4}$ \\
(4) last grade math & & - & -.03 & .03 & -.03 & .03 \\
(5) Sport hobby & & & - & -.01 & .00 & .01 \\
(6) informal skills & & & & - & .00 & -.02 \\
(7) first name & & & & - & .01 \\
\end{tabular}

B. Skilled worker positions $(N=2112$ vignettes $)$

\begin{tabular}{lrrrrr}
\hline & $(2)$ & $(3)$ & $(4)$ & $(5)$ & $(6)$ \\
\hline (1) dropout & .00 & .01 & .00 & .00 & .01 \\
(2) gpa school & - & .03 & .03 & .01 & .05 \\
(3) gpa university & & - & .00 & .02 & -.01 \\
(4) informal skills & & & - & .00 & .01 \\
(5) first name & & & & - & .00 \\
(6) fit betw. fos and job & & & & & -
\end{tabular}

C. HE graduate positions $(N=2010$ vignettes $)$

\begin{tabular}{lrrrrrrrr}
\hline & $(2)$ & $(3)$ & $(4)$ & $(5)$ & $(6)$ & $(7)$ & \multicolumn{1}{c}{$(8)$} & $(9)$ \\
\hline (1) dropout & .00 & .00 & .00 & -.01 & .00 & .01 & .01 & .00 \\
(2) gpa school & - & -.03 & .00 & .00 & -.01 & .01 & -.01 & .02 \\
(3) gpa university & & - & .01 & .02 & -.05 & -.03 & .00 & -.02 \\
(4) informal skills & & & - & .00 & -.04 & .01 & .01 & .02 \\
(5) first name & & & & - & .00 & .01 & .01 & .02 \\
(6) fit betw. fos and job & & & & & - & .01 & -.01 & -.01 \\
(7) internship & & & & & & - & .01 & -.01 \\
(8) English skills & & & & & & & & -.01 \\
(9) abroad experience & & & & & & & \\
\hline
\end{tabular}

Note: fos $=$ field of study. Significant coefficients $(\mathrm{p}<.05)$ are in bold. 


\section{Appendix I: Alternative measurement of the dependent variable}

\begin{tabular}{lcccccc}
\hline & \multicolumn{2}{c}{$(1)$} & \multicolumn{2}{c}{$(2)$} & \multicolumn{2}{c}{ (3) } \\
& Apprenticeship positions & \multicolumn{2}{c}{ Skilled worker positions } & \multicolumn{2}{c}{ HE graduate positions } \\
\hline & Hire & Invite & Hire & Invite & Hire & Invite \\
& $\mathrm{B}(\mathrm{SE})$ & $\mathrm{B}(\mathrm{SE})$ & $\mathrm{B}(\mathrm{SE})$ & $\mathrm{B}(\mathrm{SE})$ & $\mathrm{B}(\mathrm{SE})$ & $\mathrm{B}(\mathrm{SE})$ \\
\hline dropout (vs. competitor) & 0.85 & 0.96 & $-17.86^{* * *}$ & $-20.94^{* * *}$ & $-25.22^{* * *}$ & $-29.20^{* * *}$ \\
& $(0.59)$ & $(0.65)$ & $(0.79)$ & $(0.90)$ & $(0.78)$ & $(0.89)$ \\
$N$ employers & 695 & 695 & 352 & 352 & 335 & 335 \\
\hline
\end{tabular}

Note: To test whether results are robust to an alternative measurement of the dependent variable, we asked employers to state the invitation probability (instead of hiring probability) for each vignette on a 11-point scale from 0-100 \%. Results are robust to this variation. Random-intercept models, standard errors in parentheses, controls: other vignette dimensions, candidate queue, firm size, sector, occupational field, vignette set and order, ${ }^{*} p<0.05,{ }^{* *} p<0.01,{ }^{* * *} p$ $<0.001$. 
Appendix J: Hiring chances of dropouts vs typical competitors, separate for IT and business jobs

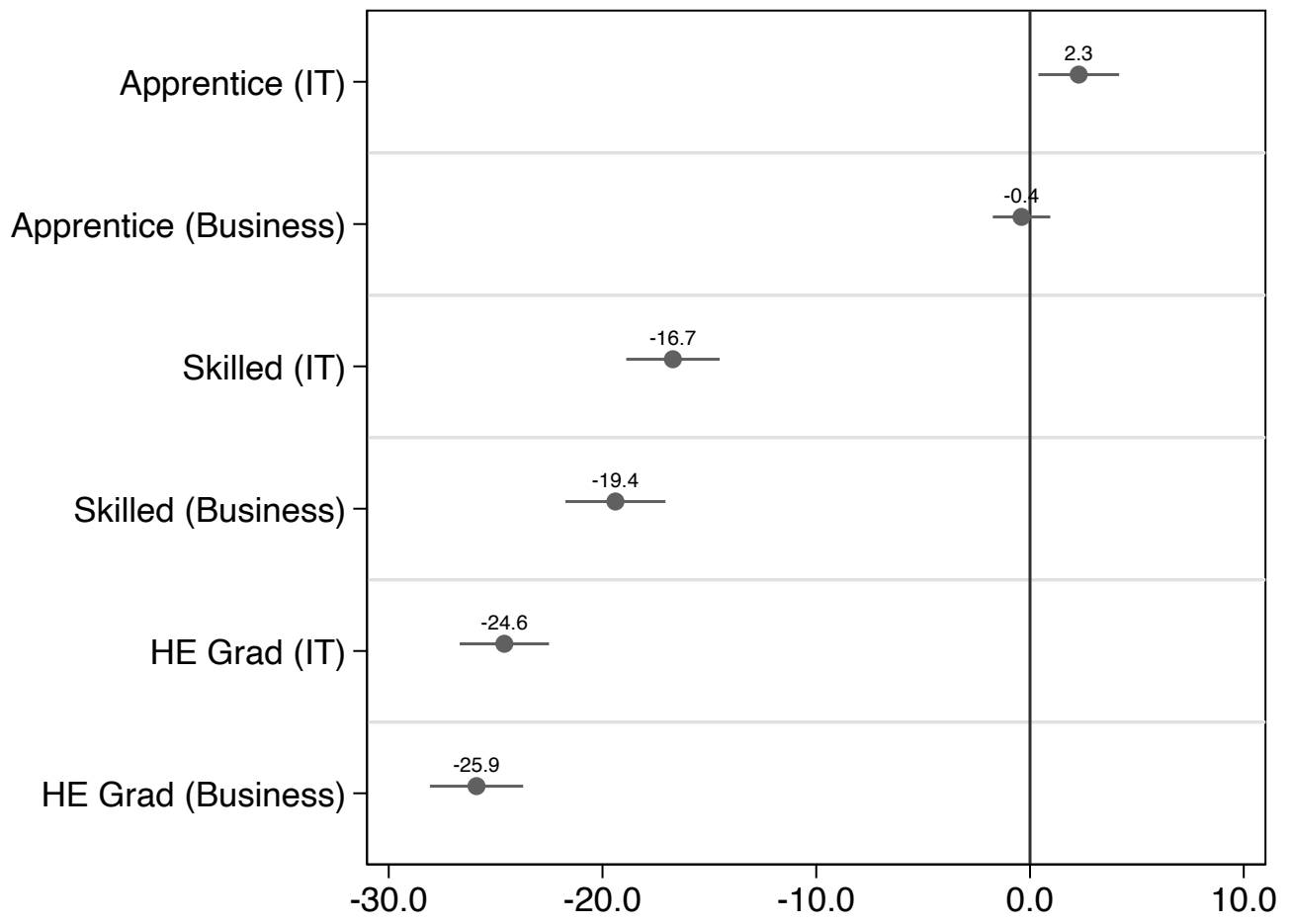

Note: IT-Business differences are insignificant (Skilled: $p=0.105$; HE Grad: $p=0.351$ ) except for apprenticeships $(p=0.014)$. The usual controls apply. 


\section{Appendix K: 'Dropouts-only' models corresponding with figure 4}

\begin{tabular}{|c|c|c|c|}
\hline & $\begin{array}{c}(1) \\
\text { Apprenticeship } \\
\text { positions }\end{array}$ & $\begin{array}{c}(2) \\
\text { Skilled worker } \\
\text { positions }\end{array}$ & $\begin{array}{c}(3) \\
\text { HE graduate } \\
\text { positions }\end{array}$ \\
\hline high acad. performance school & $1.96^{* * *}$ & $2.70^{*}$ & $1.66^{+}$ \\
\hline (vs. bad) & $(0.55)$ & $(1.09)$ & $(0.88)$ \\
\hline high acad. performance univers. & $4.33^{* * *}$ & $4.31^{* * *}$ & $4.76^{* * *}$ \\
\hline (vs. bad) & $(0.56)$ & $(1.03)$ & $(0.86)$ \\
\hline late dropout & $-1.85^{* * *}$ & $5.59^{* * *}$ & $8.75^{* * *}$ \\
\hline (vs. early) & $(0.55)$ & $(1.14)$ & $(0.89)$ \\
\hline high fit fos - asp. occ & $7.23^{* * *}$ & 0.48 & 0.49 \\
\hline 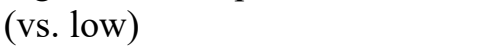 & $(0.55)$ & $(1.10)$ & $(0.87)$ \\
\hline informal skills & $4.73^{* * *}$ & $2.08^{*}$ & $1.59^{+}$ \\
\hline (vs. not) & $(0.56)$ & $(1.05)$ & $(0.86)$ \\
\hline internship & $6.70^{* * *}$ & $2.46^{*}$ & $3.38^{* * *}$ \\
\hline (vs. not) & $(0.55)$ & $(1.06)$ & $(0.89)$ \\
\hline good german grade school & $4.49^{* * *}$ & - & - \\
\hline (vs. bad) & $(0.56)$ & & \\
\hline good math grade school & $5.23^{* * *}$ & - & - \\
\hline (vs. bad) & $(0.55)$ & & \\
\hline teamsport & $0.96^{+}$ & - & - \\
\hline (vs. indiv.) & $(0.55)$ & & \\
\hline english $\mathrm{C} 1$ skills & & - & -1.19 \\
\hline (vs. lower) & & & $(0.87)$ \\
\hline studied abroad $1 \mathrm{sem}$ & & - & $2.05^{*}$ \\
\hline (vs. not) & & & $(0.88)$ \\
\hline middle class name & 0.43 & 0.17 & -1.22 \\
\hline (vs. lower class name) & $(0.56)$ & $(1.18)$ & $(0.88)$ \\
\hline \multirow[t]{2}{*}{ Constant } & $38.44^{* * *}$ & $35.33^{* * *}$ & 1.01 \\
\hline & $(4.20)$ & $(8.23)$ & $(8.25)$ \\
\hline SD (employer) & $14.84^{* * *}$ & $19.54^{* * *}$ & $16.53^{* * *}$ \\
\hline SD (vignette) & $14.25^{* * *}$ & $(1.01)$ & $(0.90)$ \\
\hline ICC & 0.52 & 0.62 & 0.65 \\
\hline Log likelihood & -11910.47 & -4989.79 & -3879.24 \\
\hline$N$ vignettes & 2780 & 1056 & 888 \\
\hline$N$ employers & 695 & 264 & 222 \\
\hline
\end{tabular}

Standard errors in parentheses, controls: candidate queue, firm size, sector, occupational field, vignette set and order ${ }^{*} p<0.05,{ }^{* *} p<0.01,{ }^{* * *} p<0.001$ 


\section{References Appendix}

Kübler, D., Protsch, P., Schmid, J., \& Solga, H. (2015). Wie Betriebe Chancen verteilen: Feldexperimente zur Bedeutung von Fächernoten, Kopfnoten und Lücken im Lebenslauf bei der Auswahl von Auszubildenden, WZBrief Bildung, No. 32.

Protsch, P., \& Solga, H. (2015). How Employers Use Signals of Cognitive and Noncognitive Skills at Labour Market Entry. Insights from Field Experiments. European Sociological Review, $31,521-32$.

KMK (2016). Abiturnoten 2015 an Gymnasien, Integrierten Gesamtschulen, Fachgymnasien, Fachoberschulen und Berufsoberschulen (Schuljahr 2014/2015). Bonn: Sekretariat der Ständigen Konferenz der Kultusminister der Länder in der Bundesrepublik Deutschland. 